\title{
Collision Damage Analysis of FPSO Hull Caisson Protection Structure
}

\section{Ozgur Ozguc}

The protection structures for the Floating Production Storage and Offloading (FPSO) caissons should be sufficiently strong to avoid contact with the caisson pipes even when the protection structure is damaged by the impact of the accompanying vessels. Collision events of protectors of appurtenances such as risers, mooring lines, and seawater lift caissons with supply vessel may cause structural damage to protection structures and even to the appurtenance structures and hull structures. This study introduces the collision impact analyses on three protective structures of FPSO against striking supply vessel whose displacement is 7,500 tons. The capacity of protection structures in view of strain energy has been assessed with simple beam FE models. The striking vessel has been modelled as a small rigid body, and impact simulation has been performed including material and geometric nonlinearities where ABAQUS Explicit tool, which is a commercial explicit code, has been used for non-linear collision analyses with protection structures. The results from the current work will be a guide to understanding the impact response of offshore structures and evaluation approaches, and will provide useful indications for the FPSO hull caisson protection design and operation. In addition, the findings obtained by the current study will be informative in the safe design of FPSO facilities.

\section{KEY WORDS}

$\sim$ Protection structures

$\sim$ Structural damage,

$\sim$ Collision event

$\sim$ Caisson pipes

$\sim$ FPSO hull vessel

Faculty of Naval Architecture and Ocean Engineering, Istanbul Technical University, Turkey

e-mail: ozguco@itu.edu.tr

doi: 10.7225/toms.v09.n02.001

This work is licensed under (cc) BY

\section{INTRODUCTION}

Collision is a major threat to the safety of a ship or other offshore facilities and can result in significant economic damage, environmental pollution, and death. The main concern regarding ship collisions with offshore structures focuses mainly on the consequences. Because the cost of repairing the offshore structure is higher than that of the striking ship, a number of studies have focused on the method of increasing the crashworthiness of the offshore structure during accidental collision scenarios (ISSC 2018).

These collision events could cause substantial damage to an offshore installation and, for a Floating Production Storage and Offloading (FPSO), the puncture of cargo tanks could result in significant spillage of hydrocarbons as well as the loss of life, disruption of safety functions and loss / delay of production. In certain situations, the damage may result in fire and explosions, or a significant structural failure leading to the FPSO's total loss.

FPSO vessel is the dominant unit for floating offshore oil and gas field production. FPSOs are efficient deep-water and ultra-deep-water production facilities and their key benefit is the ability to store and process the hydrocarbons.

Wang and Pedersen (2007) reviewed the work and analyses relating to ship-FPSO collision risk assessment. The emphasis was on the current requirements, FPSO collision occurrence, FPSO collision design scenarios, collision dynamics, impacts and acceptance requirements. The study developments of the collision and grounding of the ships have been implemented since the 1990s. Issues unique to ship-FPSO collisions have been addressed which deserve further development.

Ozguc (2015) evaluated the collision strength of SemiSubmersible type CPF (Central Processing Facility) riser safety frame (RPF) and protection net (PN) supports. The PRF and PN supports are evaluated for their collision capacity when a supply vessel collides with them. It was estimated that the vessel 
colliding from the north side is 18,000 tons and the one colliding from the east / west side was considered as 7,000 tonnes in accordance with the NORSOK N-004 code. The paper focused on general methodology and design of CPF accident scenarios using more sophisticated tools such as the non-linear FEM which predicts more accurately the structural responses during and after a collision. There were two separate designs for the supports for RPF and PN and, thus, there are four systems such as RPF-01, RPF-02, PN-01, and PN-02 respectively. The estimated kinetic energy from the North side was 20MJ for the collision. The east / west side of the collision energy was $14 \mathrm{MJ}$ for side collision, and $11 \mathrm{MJ}$ for bow / stern collision. Collision energy and plastic stress parameters were employed to predict the collision capacities of the RPF and PN supports for the specified collision energies along the period of the structures.

Cho et al. (2017) introduced the structural design method, and non-linear commercial packages were used for the analysis of collisions. Non-linear collision analyses using commercial software tools, however, were time-consuming and costly to run, particularly during the initial design stage. Within the analysis, the first use of collision test results on single pipes and $\mathrm{H}$-shape pipes was conducted to substantiate the adopted commercial package. Afterwards, a detailed parametric analysis was carried out by modifying the variables of design. A basic analytical expression was extracted assuming the striking vessel's kinetic energy had been dissipated by plastic pipe elongation and plastic hinges rotation. Using the results of the parametric analysis, design equations were obtained for calculating the maximum deflection and overall bending damage which could consider the effects of local denting and dynamic behaviour. In addition, an equation was also developed to determine the degree of local damage to the denting. The established technique was substantiated numerically using the expected magnitude of the damage to a real protection structure.

Ning et al. (2013) developed numerical methods to assess the structural integrity of a generic Spar hull in collision with a large supply vessel and to expose its progressive characteristics of the collision damage. The analysis of dynamic and non-linear finite elements is carried out for two collision scenarios using ABAQUS / Explicit tool, respectively. One was a practical simulation where the impact kinetic energy controlled by an initial velocity of impact and a ship's total mass during the collision was slowly depleted. The other was a simpler theoretical approach where a ship bow's impact velocity was constant during the collision, or the total impact energy was infinite. Progressive collision damages of the hull structures were accurately recorded for structural integrity evaluation using a combination of optimized material progressive damage models and Mises plasticity.

Hagen (2018) studied the collision damage in the Sevan 1000 FPSO when subjected to impacts from a 150,000 deadweight tonnage shuttle tanker and two types of supply vessels. The emphasis was on the shuttle tanker impacts. The objective was to determine energy dissipation involved in the drive-off impacts, and to study the relative strength and the local structural response in both the striking ship and the struck FPSO. The impact scenarios were defined by upper limit driveoff velocities and drafts corresponding to the initial and final offloading phase. Both head-on and glancing (non-central) impacts were studied for each scenario. A finite element model of the Sevan 1000 FPSO was created in the software Sesam GeniE and imported into the numerical code LS-DYNA for non-linear finite element analysis.

Ju and Jang (2019) evaluated the crashworthiness of the striking vessel and the struck vessel when the collision occurs because it can cause severe consequences. In this study, a simplified method was suggested for small-scale ship collision event and compared with the solution obtained from the finite element method. The shapes of the striking vessel and struck vessel were selected as a bow (bulbous bow and stem) and a double hulled structure respectively. From the finite element results it was confirmed that the stem case was more vulnerable than the bulbous bow case because its sharp shape could cause the local failure of struck vessel much earlier.

Ozguc (2019) focused on the general approach and design of FPSO accident scenarios using more advanced methods such as the non-linear FEM used in order to provide structural responses during and after a collision. Due to the various collision scenarios and impact energy levels, the degree of FPSO hull damage was assessed using the criteria found in the NORSOK Standard. The accident case of 5 years on-site setting was accounted for the Accidental Limit State (ALS). The different collision scenarios were described as supply vessel collision bow on, supply vessel collision side on, supply vessel collision stern on, and take tanker collision bow on off. Conservatively, the impacting vessel during the collision (full energy consumed by the FPSO) was deemed non-deforming. Damage assessment to FPSO hull, including foundations for flare and flares, aft muster station, offloading reel and piping, and safety of green water above cargo deck, was investigated

The objective of this study is to carry out the collision impact analyses on three protective structures of FPSO against striking a supply vessel with displacement of 7,500 tonnes. The capacity of protection structures in view of strain energy is assessed with simple beam FE models. The striking vessel is modelled as a small rigid body and impact simulation is being performed including material and geometric nonlinearities, where ABAQUS/ EXPLICIT, which is a commercial explicit code, is used for nonlinear collision analyses with protection structures. Collision events of protectors of appurtenances (e.g. risers, mooring lines, and seawater lift caissons) with the supply vessel may cause structural damage on the protection structures, and even on the appurtenance structures and hull structures. Therefore, these 
protective structures should be designed to withstand accidental collision with the supply vessel.

\section{FPSO VESSEL DESIGN}

Single bottom and double side hull is designed as shown in Figure 1 with topsides weighing 32,300 tons. This has a refining capacity of 200,000 barrels of oil and 150 million cubic feet of gas a day, and a storage capacity of around 1.9 million barrels of crude oil. It has living quarters that can accommodate about 150 employees. The FPSO is moored in a fixed position, and the suction piles and ground chain are linked. The facilities at the
FPSO are planned for a service life of 20 years. The topside control system of FPSO is designed to suit 21 wells and a fourth subsea separation unit. Such subsea production lines, injection lines and risers to a spread moored the FPSO.

The principle dimensions of FPSO are given as follows:

Overall Length (L): 325.05 m,

- $\quad$ Length between perpendiculars (Lbp): 325.00 m,

- Moulded Breadth (B): $61.00 \mathrm{~m}$,

- $\quad$ Moulded Depth (D): 32.00 m,

- Design Draft (Td): 24.58 m,

- Scantling Draft (Ts): 25.55 m,

- $\quad$ Block Coefficient for Scantling (Cb): 0.983.
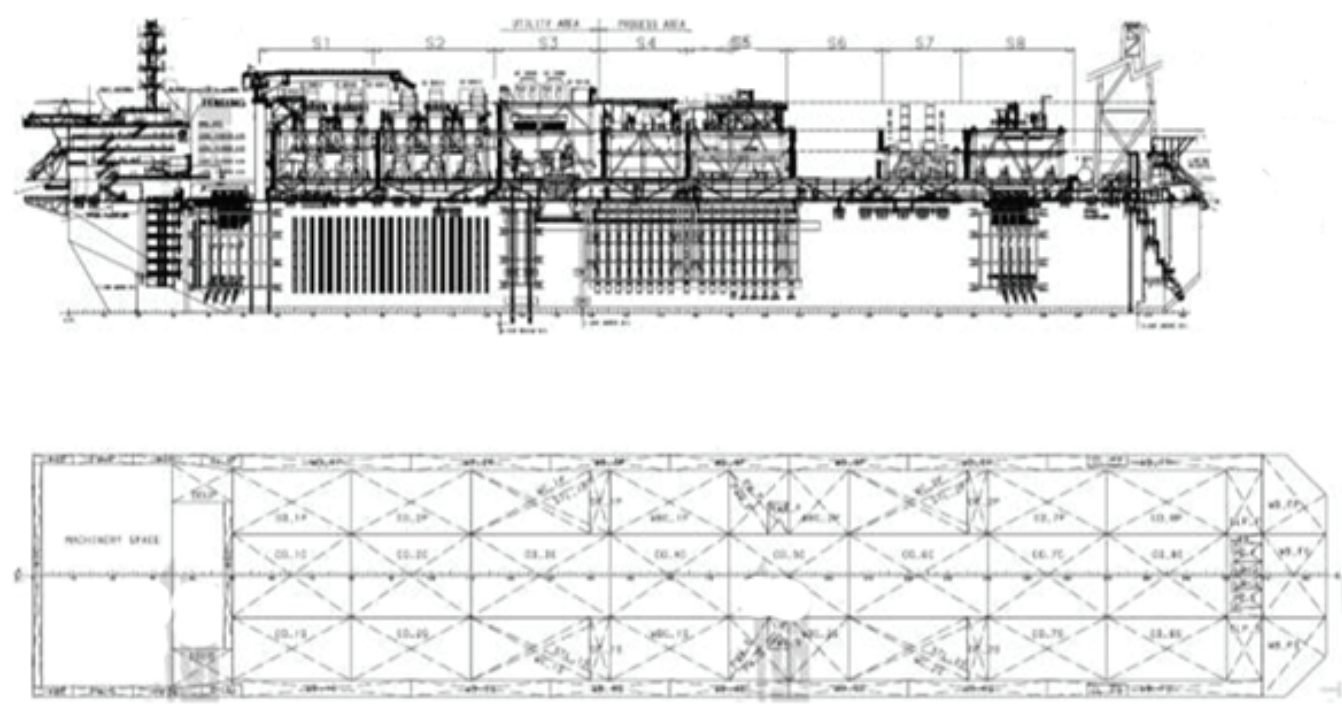

Figure 1.

FPSO vessel general arrangement.

\section{DESIGN REQUIREMENTS OF IMPACT ENERGY}

Impact energy to be considered in the protectors' collision impact analyses is shown in Table 1. The locations considered in the collision impact analyses are illustrated in Figure 2.

Table 1.

Levels of impact energies required for collision impact analyses of protectors

\begin{tabular}{|c|c|c|c|c|c|c|c|}
\hline \multicolumn{8}{|c|}{ Protectors } \\
\hline $\begin{array}{l}\text { Collision } \\
\text { Position }\end{array}$ & Loading & Acceptance Criteria & $\begin{array}{l}\text { Colliding } \\
\text { Direction }\end{array}$ & Speed & $\begin{array}{l}\text { Colliding } \\
\text { Vessel }\end{array}$ & Displacement & $\begin{array}{l}\text { Impact } \\
\text { Energy }\end{array}$ \\
\hline \multirow{2}{*}{$\begin{array}{l}\text { Riser/ } \\
\text { Mooring/ } \\
\text { Seawater Lift } \\
\text { Caisson }\end{array}$} & \multirow[t]{2}{*}{ Accidental } & \multirow{2}{*}{$\begin{array}{l}\text { Energy absorbed by plastic } \\
\text { deformation (clearance } 300 \mathrm{~mm} \text { for } \\
\text { riser only) }\end{array}$} & Bow & $1 \mathrm{~m} / \mathrm{s}$ & Supply Vessel & $7,500 \mathrm{t}$ & $4.2 \mathrm{MJ}$ \\
\hline & & & Side & & & & $5.3 \mathrm{MJ}$ \\
\hline
\end{tabular}




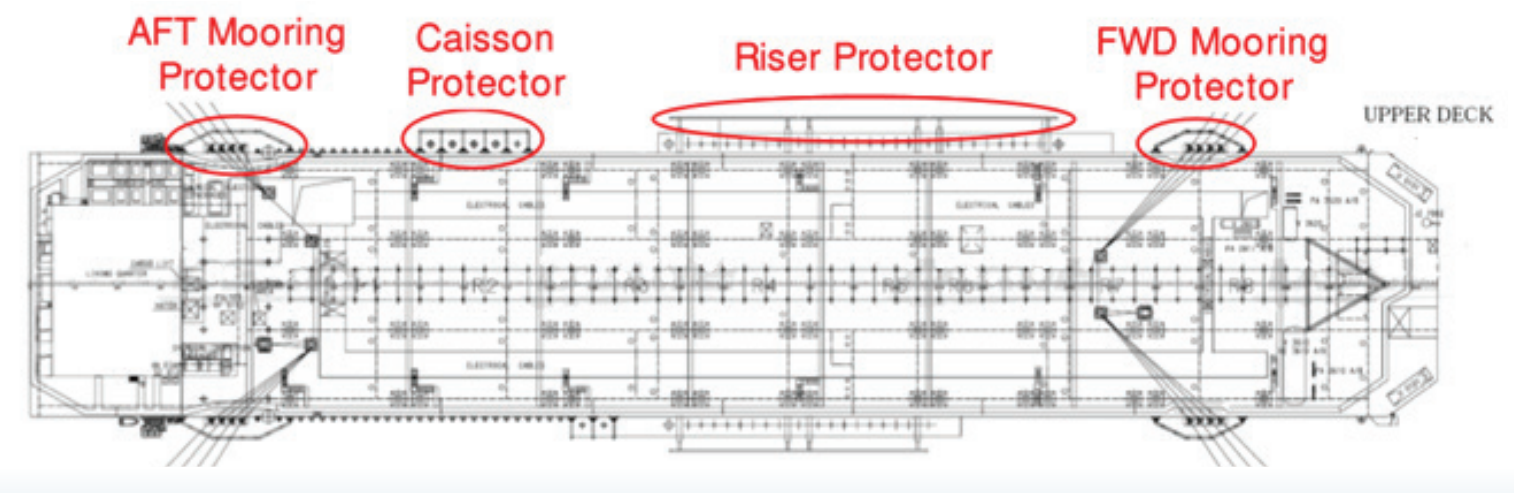

Figure 2.

Description of locations for collision impact analyses of the protectors.

Collisions on side shell and stern hull plating of the FPSO are assumed to be caused by a 7,500 ton supply vessel. The impact velocities are calculated as Eq.1.

$E=0.5(M+A d) V^{2}$

$M=$ striking vessel displacement $(\mathrm{t})$

Ad $=$ Added mass $(\mathrm{t})$

$V=$ Impact velocity $(\mathrm{m} / \mathrm{s})$

A supply vessel with a displacement of 7,500t will be considered in the collision event with protection structures of appurtenances such as risers, mooring lines, and seawater lift caissons. The impact of the 7,500 ton supply vessel at the speed of $1 \mathrm{~m} / \mathrm{s}$ causes kinetic energy of $4.2 \mathrm{MJ}$ in bow/stern impact and $5.3 \mathrm{MJ}$ in side on impact with an added mass factor of $10 \%$ and $40 \%$ of the displacement of the colliding vessel respectively. The protection structures may be subjected to significant plastic deformation, but the risers (not other protected structures) should remain undamaged with a minimum clearance of $300 \mathrm{~mm}$ between the deformed protector and the risers. The other appurtenances should remain untouched during the deformation of protection structures.

The striking vessel is assumed to be a rigid body and this assumption is considered to give conservative results in view of safety. In addition, the FPSO is assumed not to move during collision events. The amount of kinetic energy absorbed to strain energy is required to be assessed as per NORSOK Standard, which allows energy dissipation by the movement of the struck vessel (FPSO). However, it is assumed that all the kinetic energy is absorbed to strain energy for the conservative approach.

\section{SCENARIOS FOR COLLISION IMPACT ANALYSES}

Various collision scenarios are taken into account in collision impact analyses. Three (3) vertical impact locations are selected considering depth and draught of typical supply vessel as well as FPSO's operating drafts. During on site, FPSO may have various drafts between minimum draft of $11.19 \mathrm{~m}$ (normal operation) and maximum draft of $24.58 \mathrm{~m}$ (full draft).

A typical supply vessel has moulded depth of $8.0 \mathrm{~m}$ with draught of $6.5 \mathrm{~m}$. This means that the bow end of the supply vessels is located $1.5 \mathrm{~m}$ above seawater level. The main dimensions of a typical supply vessel are summarized in Table 2.

Table 2.

Main dimensions of typical supply vessel.

Overall length $\quad 90.00 \mathrm{~m}$

\begin{tabular}{ll}
\hline Length waterline & $78.00 \mathrm{~m}$ \\
\hline Overall beam & $19.00 \mathrm{~m}$ \\
\hline Moulded depth & $8.00 \mathrm{~m}$ \\
\hline Draught & $6.50 \mathrm{~m}$ \\
\hline Max. dead weight & $3,800 \mathrm{t}$ \\
\hline Light displacement & $3,700 \mathrm{t}$ \\
\hline Loaded displacement & $7,500 \mathrm{t}$ \\
\hline Cruise speed & 12 knots \\
\hline Max. speed & 16 knots
\end{tabular}

Two different attack angles ( 0 / 90 degrees) were considered mainly in collision with protection structures to evaluate the protector itself and to obtain reaction forces that should be used for the design of support structures. Zero degree attack angle 
was accounted by supply vessel and was applied to mooring protectors and seawater lift caisson protectors on the vessel landing area (Zhang, 1999). In addition, the slanted parts of mooring protectors were considered to be impacted by supply vessel perpendicular to the protectors (about 42 degrees with FPSO). Table 3 summarizes collision scenarios to be considered.

Table 3.

Collision scenarios for the simulations.

\begin{tabular}{llll} 
& Protection Structures & & Caisson \\
\hline FPSO Draft & Riser & Mooring & \\
\hline Collision Angle & Three drafts (full/mid/min.) & & $0 / 90$ degrees \\
\hline Note & 90 degree & $0 / 42 / 90$ degrees & \\
\hline
\end{tabular}

The proposed locations for collision impact analyses on protectors are illustrated in Figure 3, while Figure 4 illustrates the attack angles for collision on protector structures.
Detailed load cases for each protector are summarized in Table 4, and sketches of impact locations for the protectors are given in Figure 5 to Figure 8.

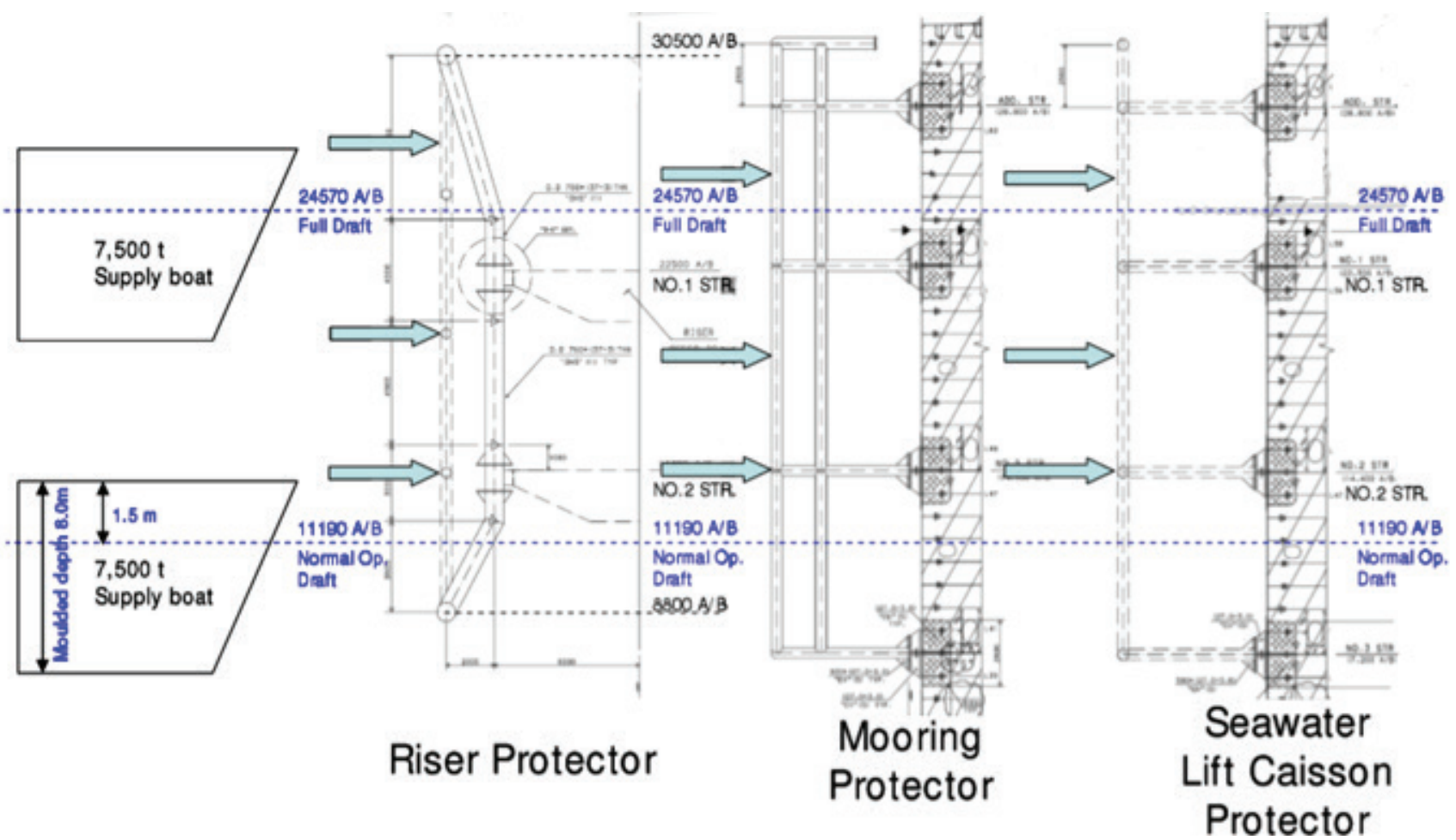

Figure 3.

Vertical locations for collision impact analyses on protection structures (NORSOK N-004). 


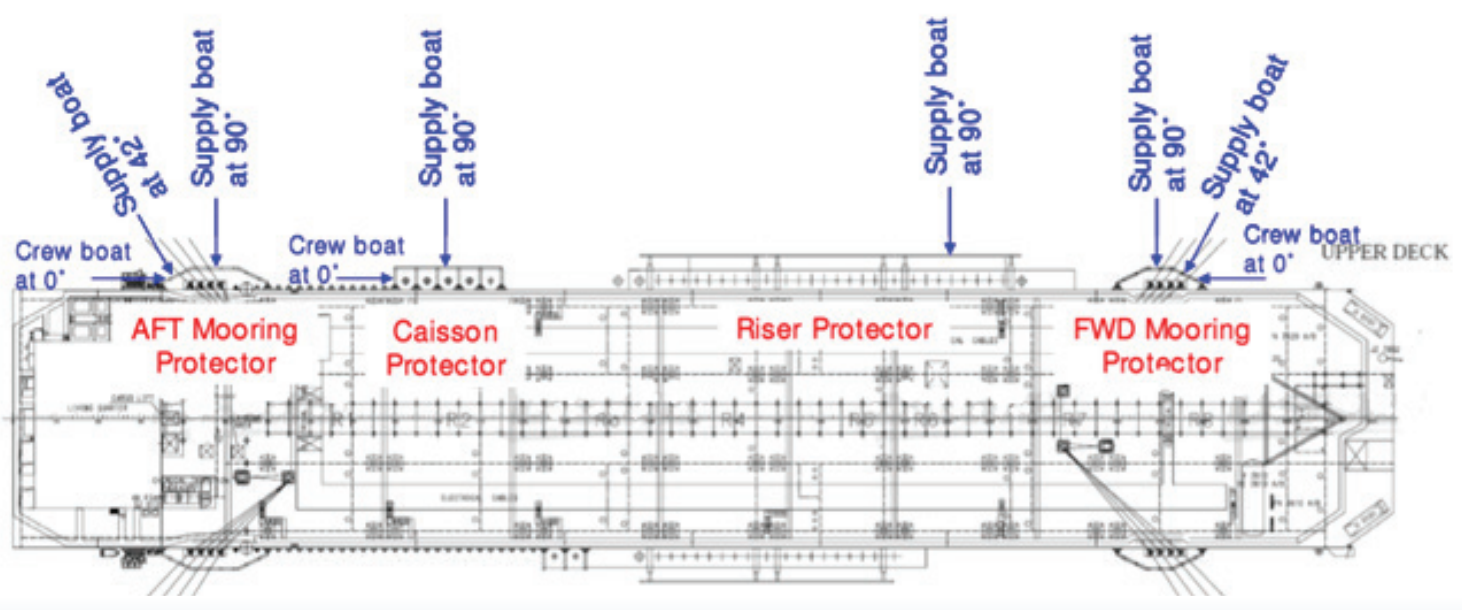

Figure 4.

Attack angles for collision impact analyses on protection structures.

Table 4.

Detailed load cases for collision impact analyses.

Riser Protector

\begin{tabular}{|c|c|c|c|c|}
\hline LC & Impact angle & Impacting vessel & Approaching direction & Energy to be absorbed \\
\hline $1 \sim 8$ & \multirow[t]{2}{*}{90 degree } & \multirow{2}{*}{$\begin{array}{l}\text { Supply vessel } \\
(7,500 t)\end{array}$} & Bow & 4.2 MJ \\
\hline $9 \sim 12$ & & & Side & $5.3 \mathrm{MJ}$ \\
\hline \multicolumn{5}{|c|}{ Mooring Protectors } \\
\hline LC & Impact angle & Impacting vessel & Approaching direction & Energy to be absorbed \\
\hline $1 \sim 5$ & 90 & \multirow{4}{*}{$\begin{array}{l}\text { Supply vessel } \\
(7,500 t)\end{array}$} & \multirow[t]{2}{*}{ Bow } & \multirow[t]{2}{*}{$4.2 \mathrm{MJ}$} \\
\hline $6 \sim 8$ & 42 & & & \\
\hline $9 \sim 11$ & 90 & & \multirow[t]{2}{*}{ Side } & \multirow[t]{2}{*}{$5.3 \mathrm{MJ}$} \\
\hline $12 \sim 14$ & 42 & & & \\
\hline 15 & 0 & Crew boat $(478 \mathrm{t})$ & Bow & $0.263 \mathrm{MJ}$ \\
\hline \multicolumn{5}{|c|}{ Seawater Lift Caisson Protectors (PORT) } \\
\hline LC & Impact angle & Impacting vessel & Approaching direction & Energy to be absorbed \\
\hline $1 \sim 9$ & 90 & \multirow{2}{*}{$\begin{array}{l}\text { Supply vessel } \\
(7,500 t)\end{array}$} & Bow & $4.2 \mathrm{MJ}$ \\
\hline $10 \sim 16$ & 90 & & Side & $5.3 \mathrm{MJ}$ \\
\hline 17 & 0 & Crew boat $(478 \mathrm{t})$ & Bow & $0.263 \mathrm{MJ}$ \\
\hline \multicolumn{5}{|c|}{ Seawater Lift Caisson Protectors (STBD) } \\
\hline LC & Impact angle & Impacting vessel & Approaching direction & Energy to be absorbed \\
\hline $1 \sim 8$ & 90 & \multirow{2}{*}{$\begin{array}{l}\text { Supply vessel } \\
(7,500 t)\end{array}$} & Bow & 4.2 MJ \\
\hline $9 \sim 14$ & 90 & & Side & $5.3 \mathrm{MJ}$ \\
\hline 15 & 0 & Crew boat $(478 \mathrm{t})$ & Bow & $0.263 \mathrm{MJ}$ \\
\hline
\end{tabular}


Bow collision was simulated by one (1) contact point instead of surface area, which might give severer results since it is certain that the bow of the striking vessel is blunt. Furthermore,

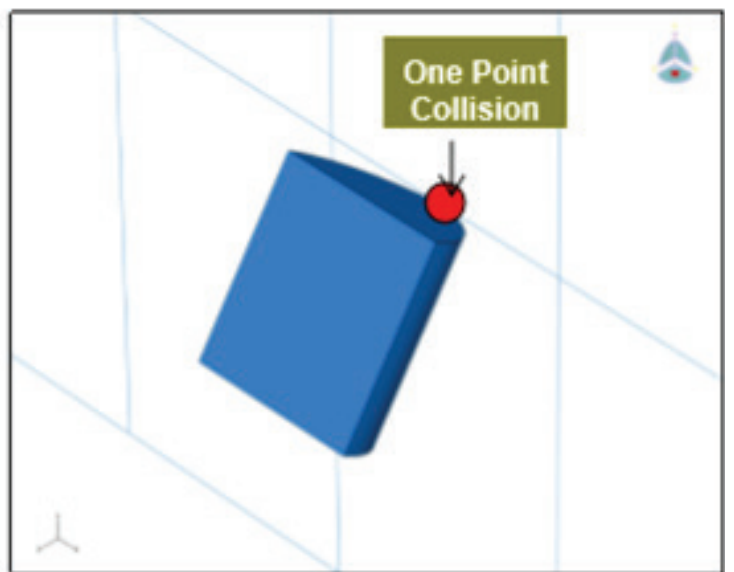

even though the supply vessel has over $90 \mathrm{~m}$ of beam, only two (2) vertical beams were taken into consideration. The striking views simulated in FEA are shown in Figure 5.

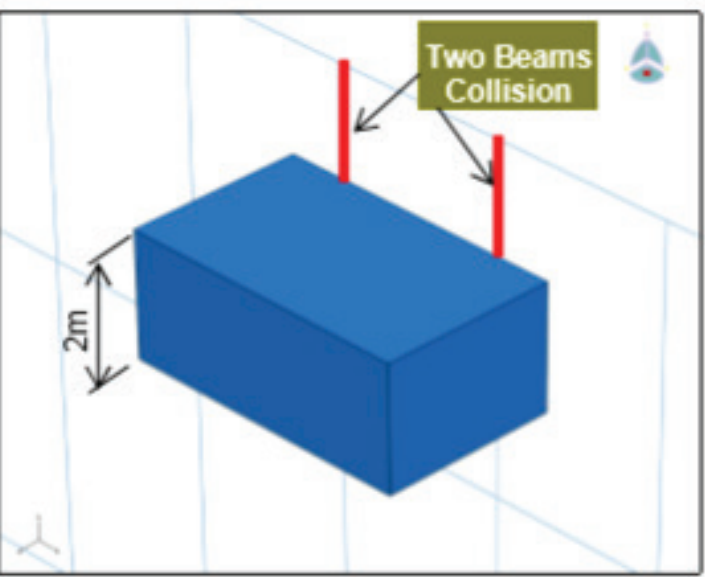

Figure 5.

Striking view simulated in finite element analyses.

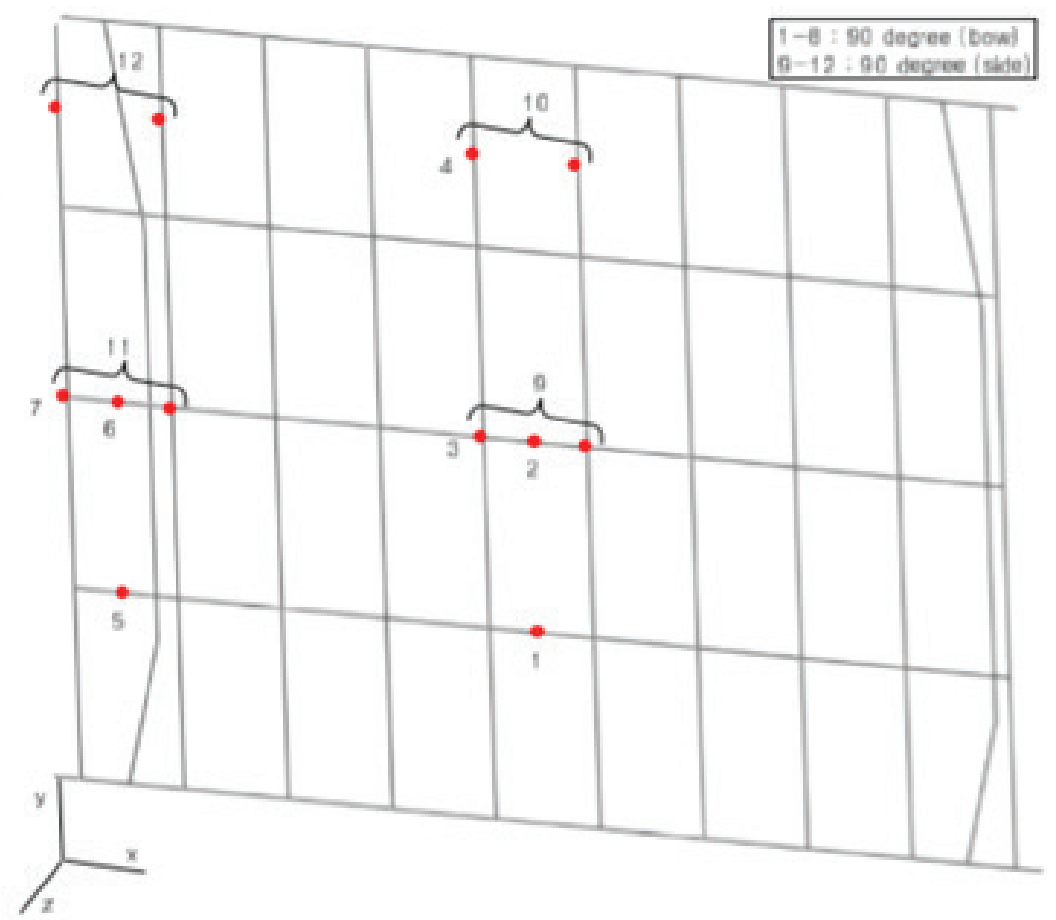

Figure 6.

Load cases and impact locations for riser protector. 


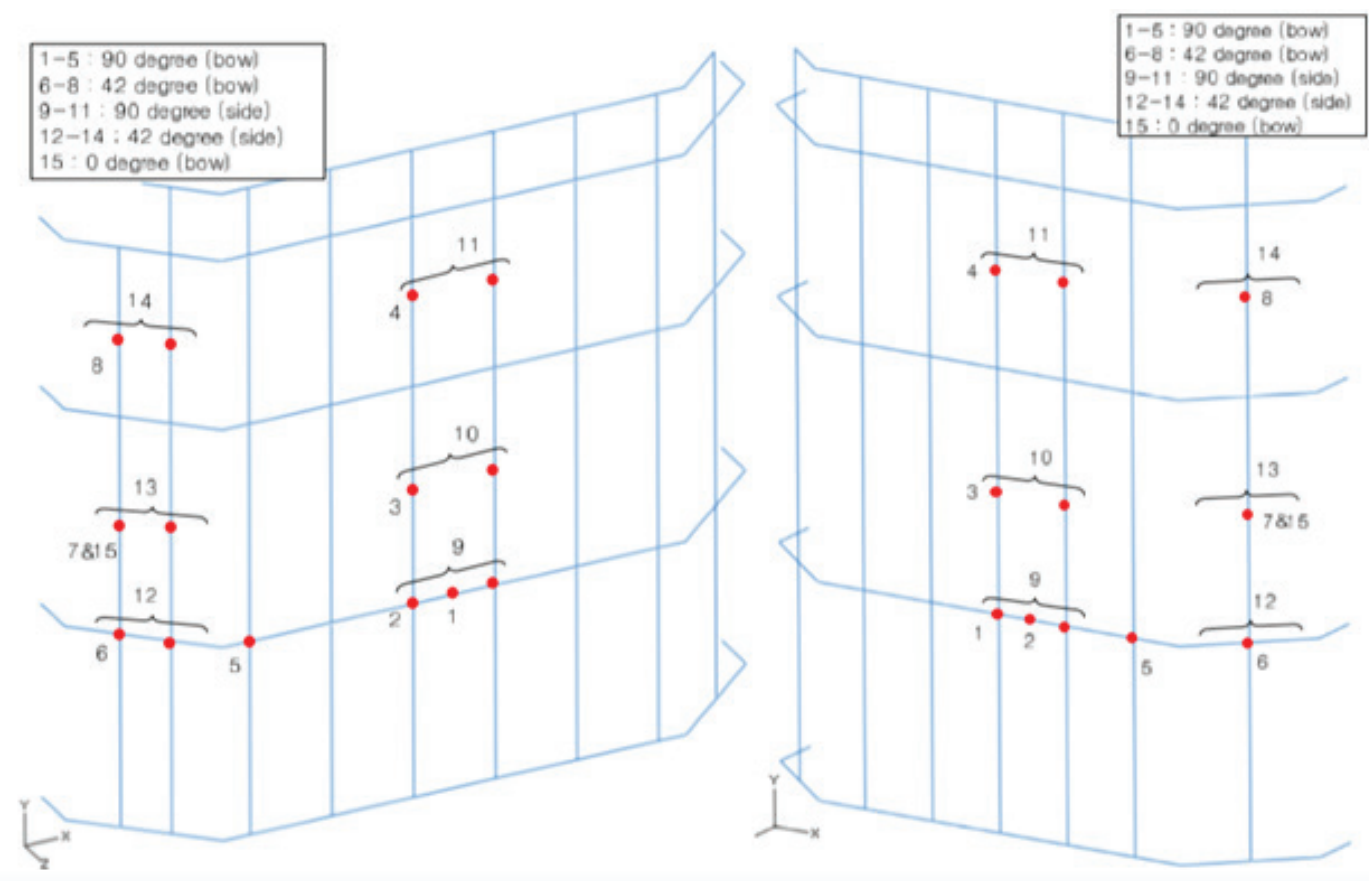

Figure 7.

Load cases and impact locations for mooring protectors (left: Aft Mooring Protector, and right: Forward Mooring Protector).
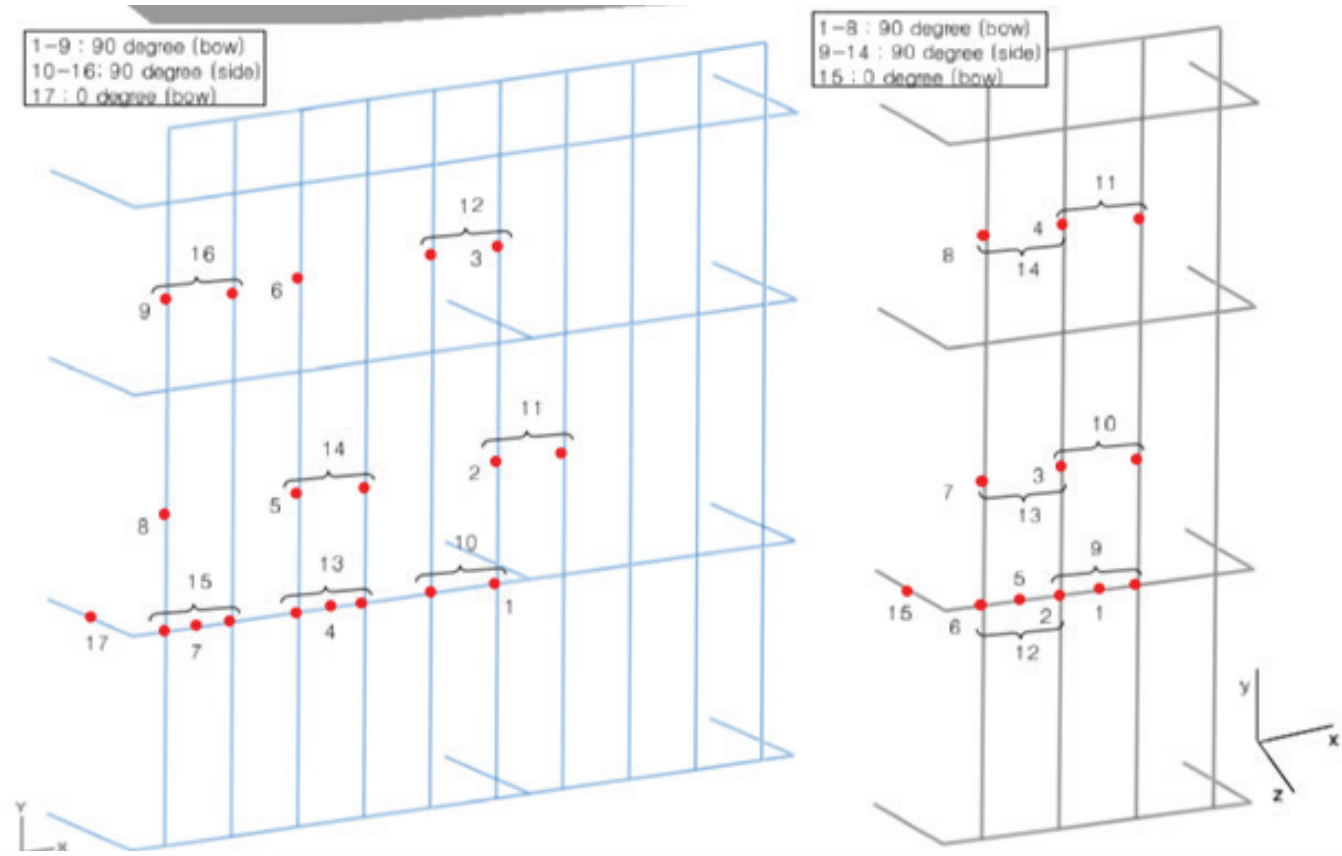

Figure 8.

Load cases and impact locations for seawater lift caisson protectors (left: PORT Caisson Protector, and right: STBD Caisson Protector). 


\section{RUPTURE STRAIN AND MATERIAL PROPERTY}

The amount of kinetic energy absorbed as strain energy must be assessed in accordance with the NORSOK standard. It is presumed, however, that all of kinetic energy is consumed in a conservative way to rupture strain. The percentage of rupture strain is also determined depending on the grade of steel, as shown in Table 5 below, as per the NORSOK Standard. Interpolation calculated the percentage of rupture strain for the grade of steel that is not specified in the table. In addition, material properties used in collision analysis are depicted in Table 6.
Table 5.

Proposed values of $\varepsilon \mathrm{cr}$ for different steel grades by NORSOK.

\begin{tabular}{ll} 
Steel Grade & Critical Strain $(\varepsilon c r)$ \\
\hline Mild & $20 \%$ \\
\hline HT 32 & $16.7 \%$ \\
\hline HT 36 & $15 \%$ \\
\hline
\end{tabular}

Table 6.

Material properties to be used in non-linear F.E. analyses (DNVGL-RP-C208)

\begin{tabular}{llll} 
Steel Grade & Mild & HT 32 & HT 36 \\
\hline Yield stress & $235 \mathrm{MPa}$ & $315 \mathrm{MPa}$ & $355 \mathrm{MPa}$ \\
\hline Elastic strain & $0.20 \%$ & $0.20 \%$ & $0.20 \%$ \\
\hline Ultimate tensile stress & $450 \mathrm{MPa}$ & $530 \mathrm{MPa}$ & $560 \mathrm{MPa}$ \\
\hline Critical failure strain & $20.0 \%$ & $16.7 \%$ & $15.0 \%$ \\
\hline Density & $7,850 \mathrm{~kg} / \mathrm{m3}$ & $7,850 \mathrm{~kg} / \mathrm{m} 3$ & $7,850 \mathrm{~kg} / \mathrm{m} 3$ \\
\hline Young's modulus & $2.06 \mathrm{e}+11 \mathrm{~N} / \mathrm{m} 2$ & $2.06 \mathrm{e}+11 \mathrm{~N} / \mathrm{m} 2$ & $2.06 \mathrm{e}+11 \mathrm{~N} / \mathrm{m} 2$ \\
\hline Poison's ratio & 0.3 & 0.3 & 0.3 \\
\hline Tangent modulus & $1,085 \mathrm{MPa}$ & $1,303 \mathrm{MPa}$ & $1,385 \mathrm{MPa}$ \\
\hline Hardening parameter & 1.0 & 1.0 & 1.0 \\
\hline Strain rate $(\mathrm{C})$ & 40.4 & 3200 & 3200 \\
\hline Strain rate $(\mathrm{P})$ & 5.0 & 5.0 & 5.0
\end{tabular}

\section{ASSESSMENT METHOD}

In this study, FE analyses focus on the assessment of a multitude of possible scenarios of ship collision and structural configurations to be analysed. An FE analysis is the most flexible method and can account for possible effects occurring as well as be used to assess the relevant factors such as impact energy, boundary conditions, material, and discrete indenter shape, and stiffness and indentation location. Assessing non-linear material behaviour is essential when determining the response of a structure.

The properties of the elastic-plastic materials should be described by application:

- An initial yield criterion;

- A hardening rule where the yield condition is modified due to the history of plastic flow;

- A flow rule that updates the plastic stiffness using an incremental stress-strain relationship.

- The explicit method of analysis for the FE has the following properties:
- $\quad$ Can manage very low dynamic response times, allowing highly discontinuous processes for large models;

- Allows for large deformations and rotations;

- It can analyse assembled parts with very general contact definitions;

- A linear geometrical deformation theory can be employed if small deformations and rotations are presumed;

- Adiabatic stress analysis may be used if heat generation is assumed to be associated with inelastic dissipation;

- $\quad$ Allows for quasi-static analysis of models with complex contact definitions;

- $\quad$ Allows the deletion of the element to the rupture model.

To check the strength of the structures against collision impact, explicit nonlinear FE simulations are carried out, including large deformation of structures and the properties of elastoplastic material. Strain hardening effect together with ultimate stress is accounted for nonlinear FE simulations as a bilinear strain-stress curve based on material grades as shown in Figure 9 and Figure 10. The fracture was determined on the basis of the critical plastic strain of the material used in accordance 
with the NORSOK standard. Figure 11 shows the properties of the material used in non-linear simulation. Ultimate stress data are average values and critical strain data are based on the NORSOK standard. The Cowper-Symonds rate enhancement formula is employed to account for the effect of strain rate on material properties as given in Eq.2, Eq.3 and Eq.4 that are shown in Figure 9 and Figure 10.

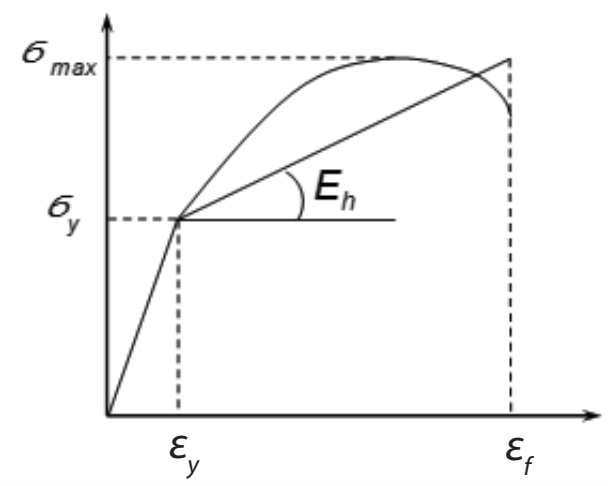

Figure 9.

Stress-strain curve for bi-linear material.

$\sigma_{p}=\sigma_{y}+\frac{E E_{h}}{E-E_{h}} \varepsilon_{p}$

$E_{h}=\frac{\sigma_{y \max }-\sigma_{y}}{\varepsilon_{f}-\varepsilon_{y}}$

$\sigma_{y}=$ Yield stress

$E_{h}^{y}=$ Hardening modulus

$\sigma_{p^{\prime}} \varepsilon_{p}=$ Plastic stress and Plastic strain

$E=$ Young's modulus

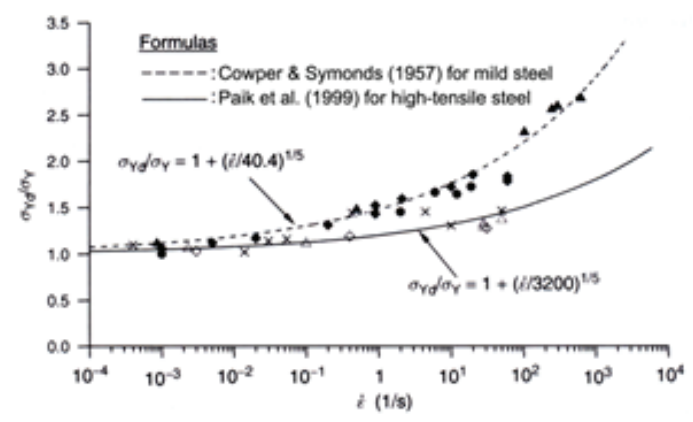

Figure 10.

Strain rate effect. $\frac{\sigma_{y d}}{\sigma_{y}}=1+\left\{\frac{\varepsilon}{D}\right\}^{1 / q}$

$\begin{array}{lll}\text { Mild steel: } & D=40.4, & q=5 \\ \text { HT steel } & D=3200, & q=5\end{array}$

It is noted that $\sigma_{y d}$ is the dynamic yield stress; $\sigma_{y}$ is the static yield stress. The material properties given to the initial configuration are in accordance with the steel quality used for the FPSO vessel. This included steel grades Mild, HT32 and HT36 as per DNVGL-RP-C208 (2019).

Collision simulation, including material and geometric nonlinearities, was performed using ABAQUS Explicit tool. To determine the strength capacity of hull plating for the supply vessel and oil tanker against collision events, advanced nonlinear FE simulation is performed because complex responses are caused by these collision events. Element properties applied in the FE models are produced by deducting full of DNVGL Ship Rules corrosion addition from rule gross scantling according to DNVGL Ship Rules Part 3, Chapter 1 requirement (2019).

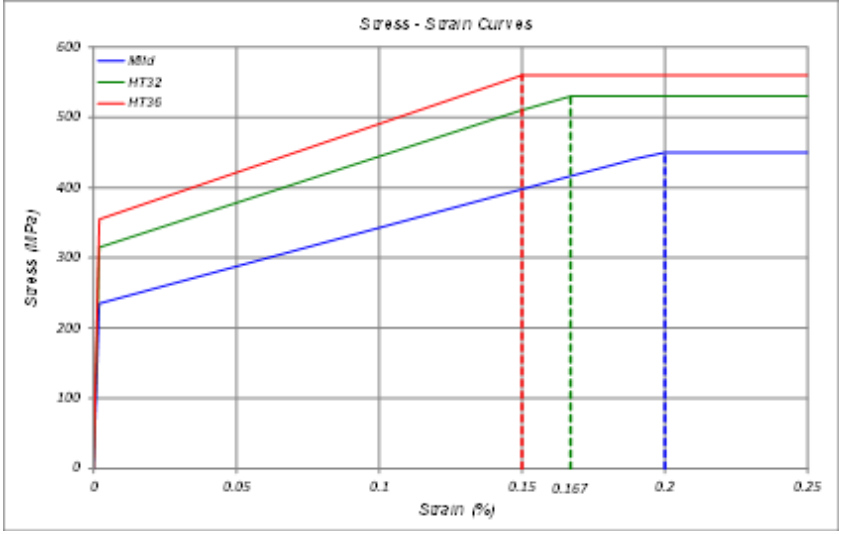

Figure 11.

Stress-strain curves for different steel grades.

\section{FINITE ELEMENT (FE) MODELS}

The capacity of protection structures in view of strain energy has been assessed with simple beam FE models. Due to the simplicity of structures, ABAQUS Explicit code has been employed for the collision simulation with protection structures. FE models of riser protector, aft mooring protector, forward (FWD) mooring protector, port caisson, starboard (STBD) caisson with bow and side impact rigid models are shown in Figures 12 to 21 . 


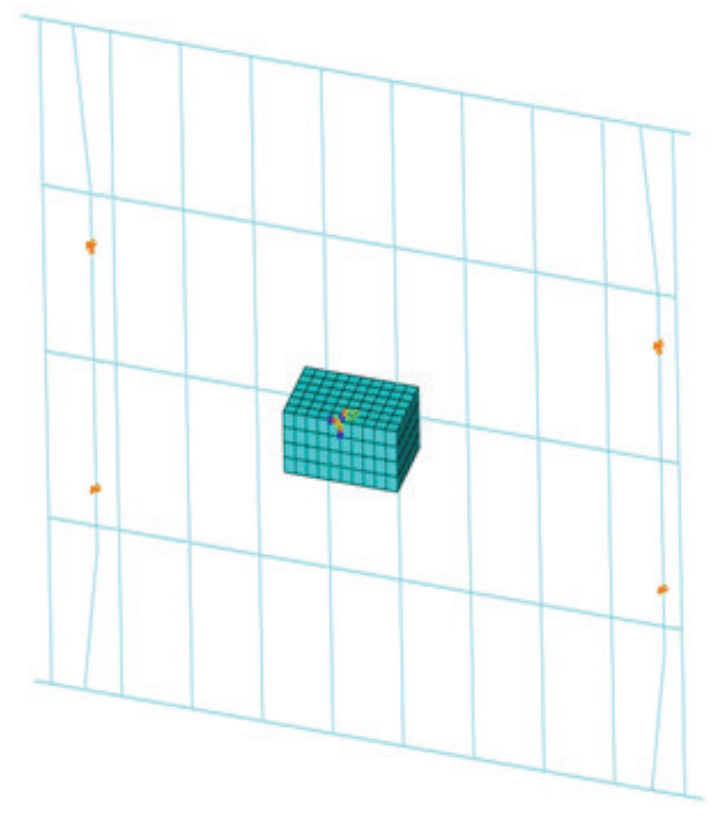

Figure 12.

FE model of riser protector and side impact rigid model.

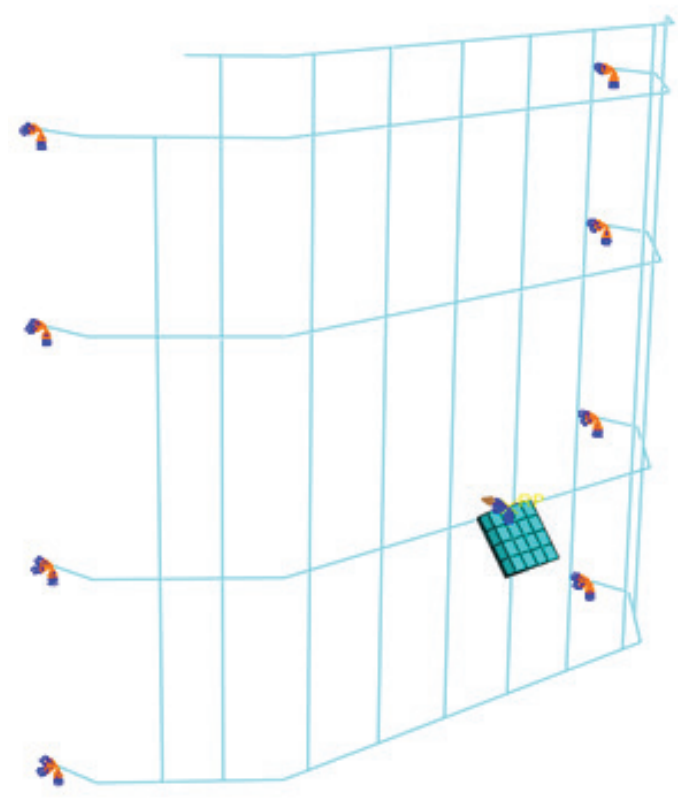

Figure 13.

FE model of AFT mooring protector and bow impact rigid model.

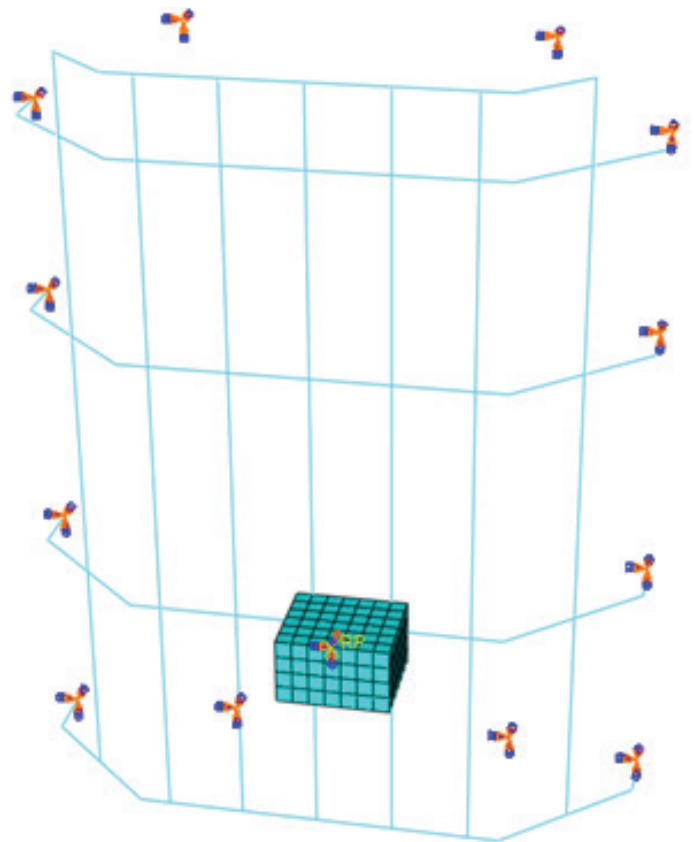

Figure 14.

FE model of FWD mooring protector and side impact rigid model.

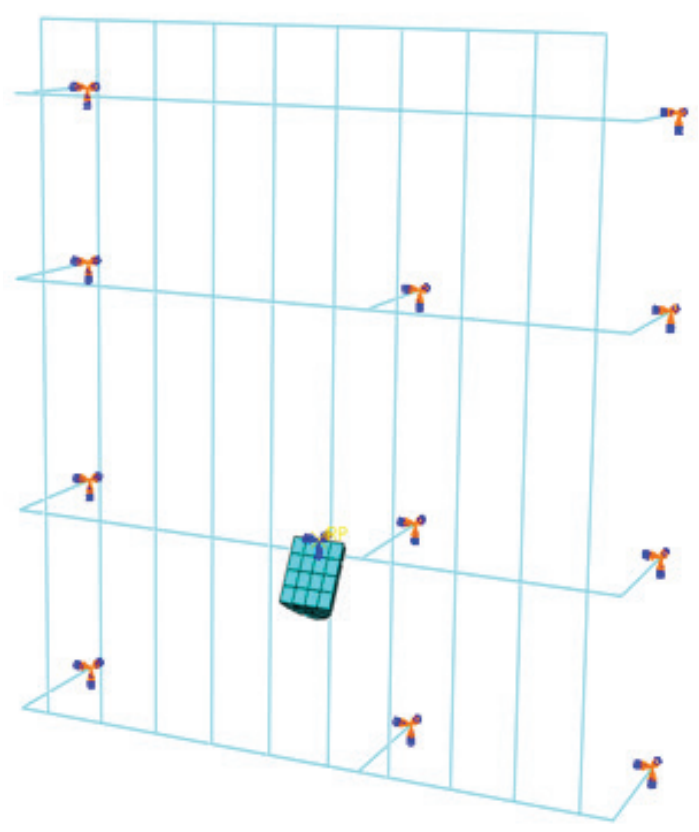

Figure 15.

FE model of PORT caisson protector and bow impact rigid model. 


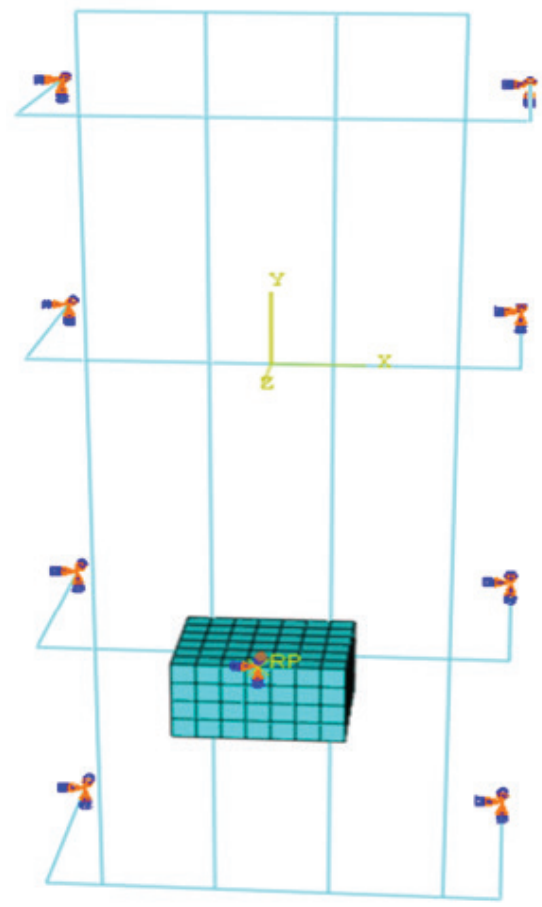

Figure 16.

FE model of STBD caisson protector and side impact rigid model.

\section{BOUNDARY CONDITIONS}

Boundary condition of each protector has been set according to the connection mechanism of protectors to the supporting structures.

For riser protectors, riser guard is clamped to 4 supports ( 2 at upper and 2 at lower), which are welded to the hull. Clamps are provided with elastometric pads and allow small rotation, as shown in Figure 17. In a practical approach, stiffness of the hull and stiffness of the clamp system have not been taken into account: upper supports are considered pinned and lower supports guided. For instance, if the upper support is assumed with pinned boundary, it is certain that the lower support does not react to lateral behaviour because the angular deformation is completely restricted at upper structure. The expected shape of protector during collision may be given as in Figure 17.

For mooring protectors and seawater lift caisson protectors, protectors are welded to supports which are also welded to hull. Hence, all the supporting locations are considered as fixed boundary, both in translational and rotational directions. The boundary conditions of supports are summarised in Table 7, and the sketch of each protector is shown in Figure 18.
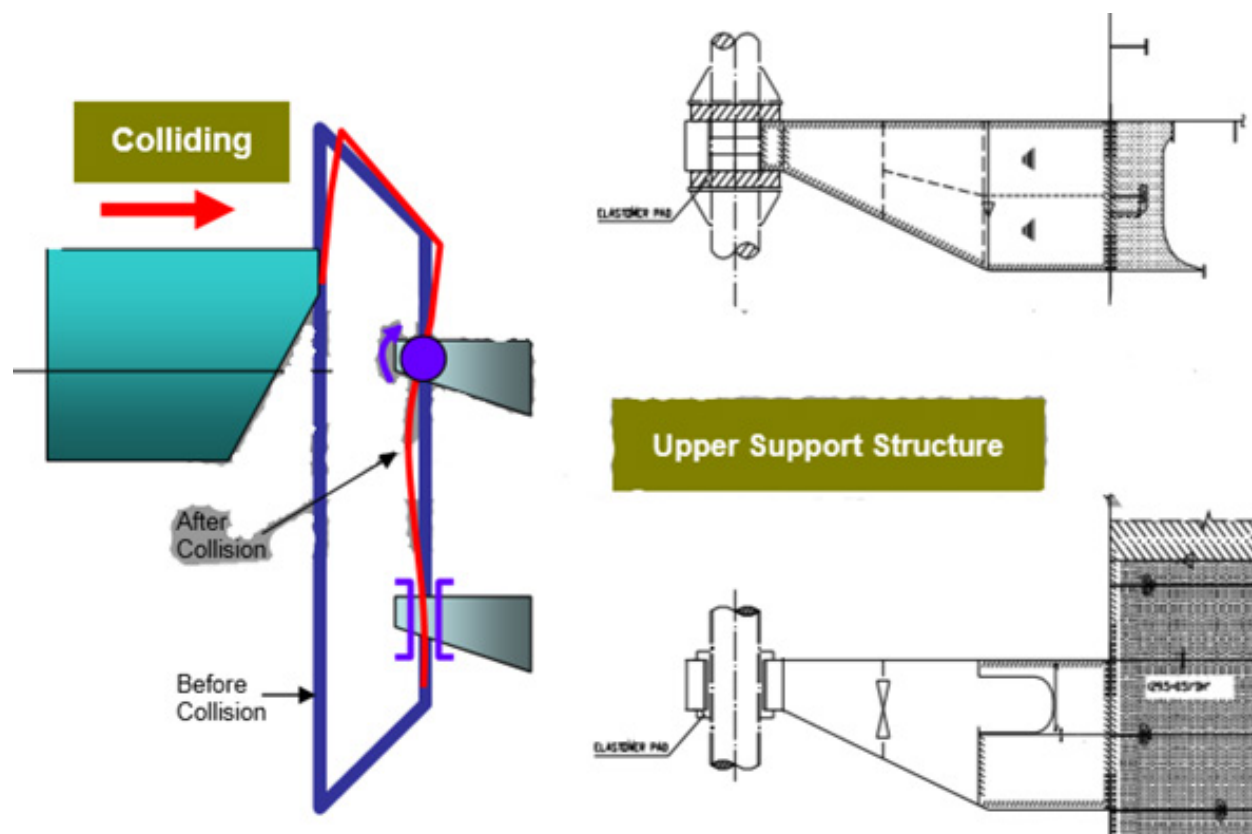

\section{Upper Support Structure}

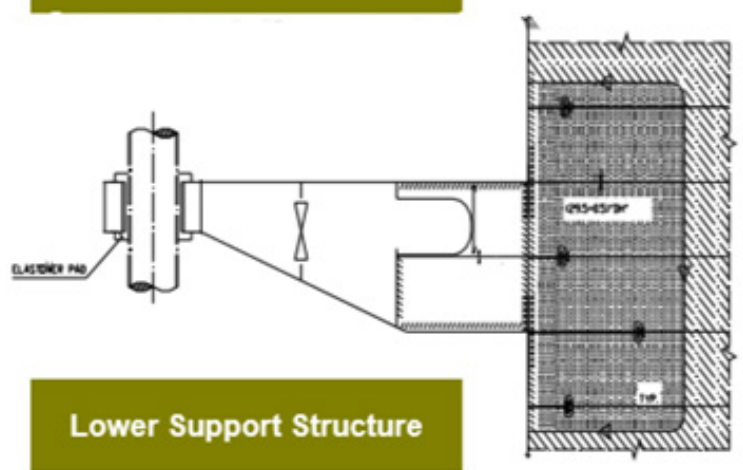

Figure 17.

Clamp and riser guard of riser protector (Upper and Lower Support). 
Table 7.

Boundary conditions of each protector.

\begin{tabular}{llll} 
Protectors & Riser protector & Mooring / Caisson protector \\
\hline Supports & Upper supports & Lower supports & All supports \\
\hline Translation & $\mathrm{UX}=\mathrm{UY}=\mathrm{UZ}=0$ & $\mathrm{UX}=\mathrm{UZ}=0, \mathrm{UY}=\mathrm{FREE}$ & $\mathrm{UX}=\mathrm{UY}=\mathrm{UZ}=0$ \\
\hline Rotation & $\mathrm{RX}=\mathrm{RY}=\mathrm{RZ}=\mathrm{FREE}$ & $\mathrm{RX}=\mathrm{RY}=\mathrm{RZ}=0$ \\
\hline
\end{tabular}

Note: $x$ is longitudinal direction

$y$ is vertical direction

$z$ is transversal direction
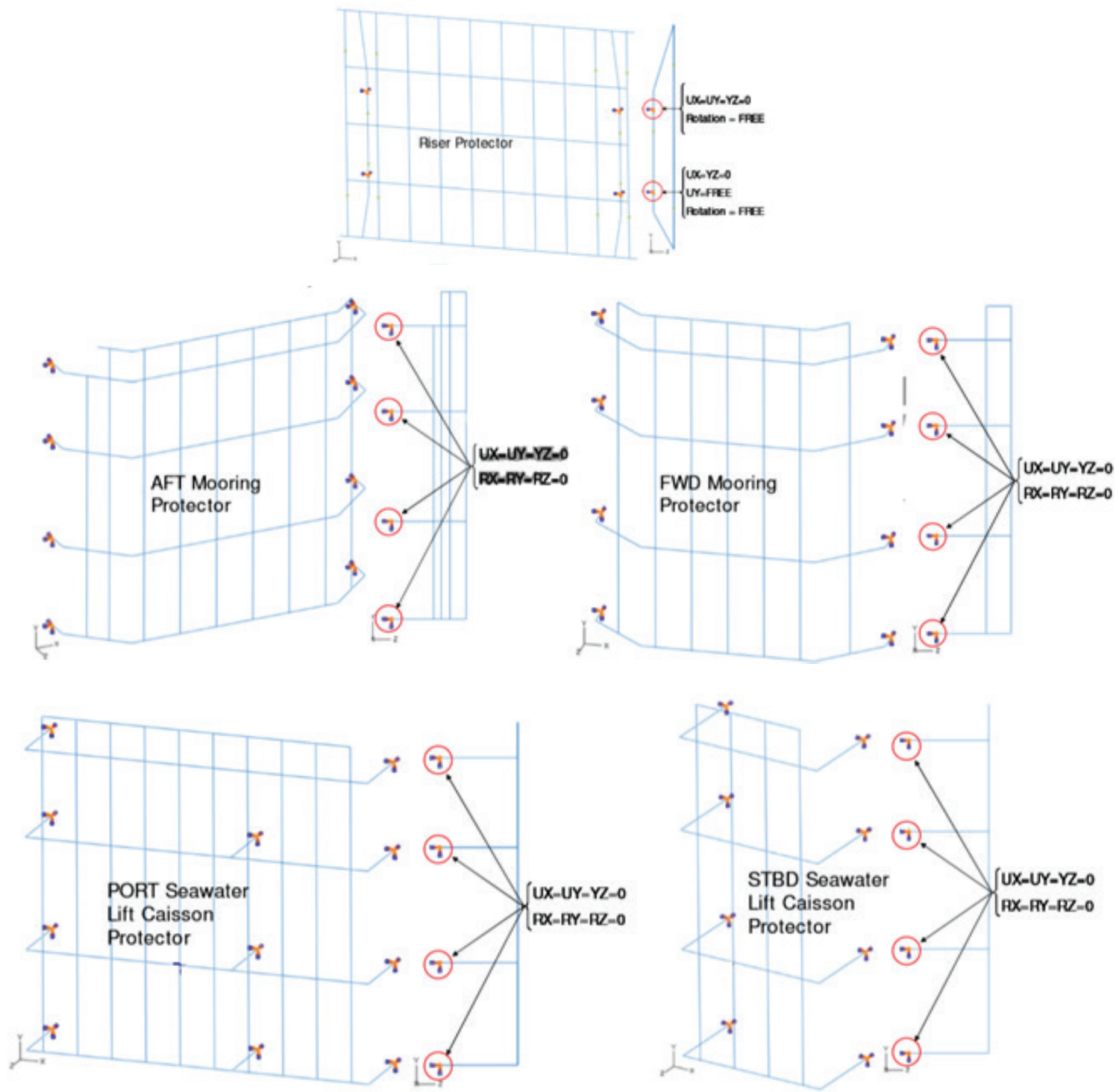

Figure 18.

Boundary conditions of protectors. 


\section{FINITE ELEMENT SIMULATION}

Collision events are simulated by giving initial speed of 1.0 $\mathrm{m} / \mathrm{s}$ to the rigid body, which represents colliding supply vessel. The mass of the rigid body varies according to the colliding directions (bow/side-on) with corresponding added mass coefficients.

During the collision the surface contact between the supply vessel and the protector is taken into consideration. An infinite coefficient of friction is used during contact phenomenon because it is considered a conservative approach to allow no slip at the contact point. The contact was defined by beam-tosurface in ABAQUS. Self-contact which may occur due to large deformation of protector is allowed, but no self-contact occurred.

\section{LOCAL DENTING EFFECT}

For local denting on the pipe surface due to the ship collision, it may be necessary to estimate the reaction force from the striking vessel (NORSOK standard N-004). The response of a beam subjected to a collision load is initially governed by bending, which is affected by and interacts with local denting under the load. The bending capacity is also reduced if local buckling takes place on the compression side. As the beam undergoes finite deformations, the load carrying capacity may increase considerably due to the development of membrane tension forces. This depends upon the ability of adjacent structure to restrain the connections at the member ends to inward displacements. Provided that the connections do not fail, the energy dissipation capacity is either limited by tension failure of the member or rupture of the connection.

Obviously, the bow collision might affect more the denting phenomenon on the surface rather than side directional collision. The local denting was looked into by considering a collision on the middle of the span of riser protector, which was chosen as an example for knowing how a certain level of denting may take place on the tube. Load Condition (LC2) is accounted for a colliding event by supply vessel's bow.

From the FE results, the reaction force of $342 \mathrm{kN}$ was calculated and compared to the critical resistance as per NORSOK Standard "N-004, Design of Steel Structures".

The critical resistance can be calculated to $279 \mathrm{kN}$, so the ratio of resistances is $1.22(=342 \mathrm{kN} / 279 \mathrm{kN})$. In accordance with the NORSOK N-004 code, the denting depth due to bow collision is required to be no more than 0.01D. Thus, considering the outer diameter of $450 \mathrm{~mm}$, the denting depth is merely $4.5 \mathrm{~mm}$, which would be negligible in the reduction of moment capacity due to local denting, which is referred to in Figures 19 and 20, according to NORSOK N-004. Finally, the effect of local denting from ship collision is not taken into account here.

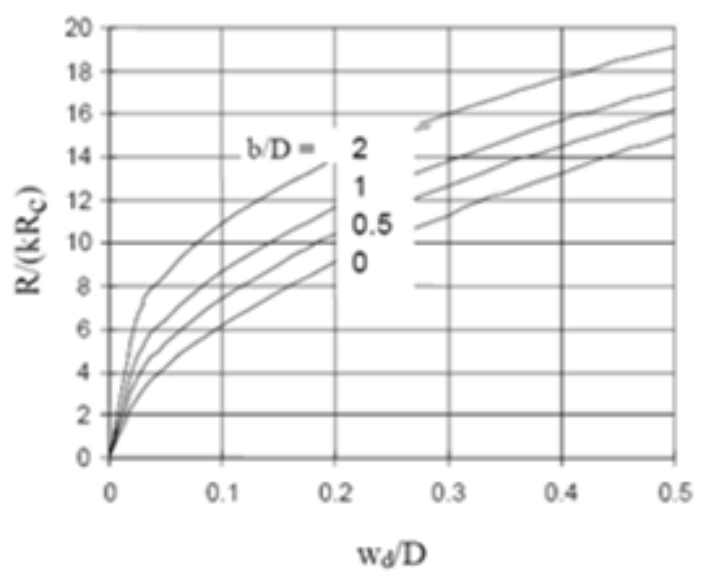

Figure 19.

Resistance curve for local denting.

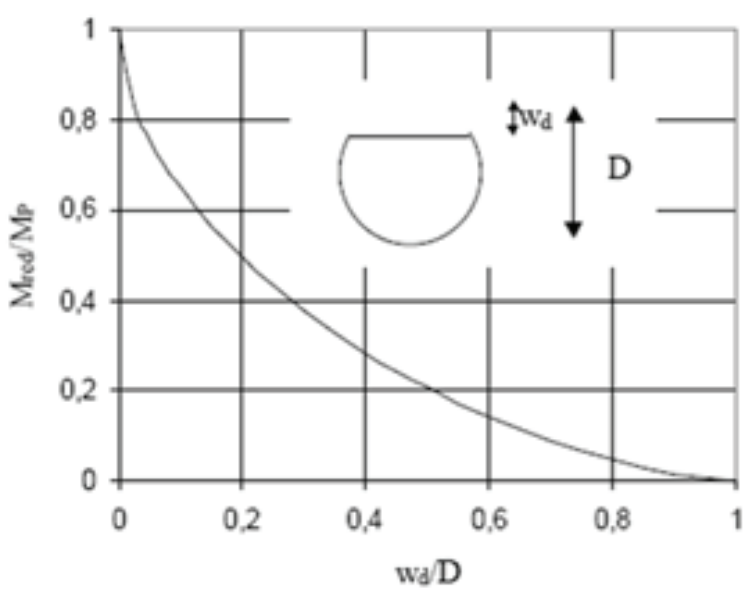

Figure 20

Reduction of Moment Capacity due to local dent.

\section{FINITE ELEMENT (FE) RESULTS}

For all the impact load cases, the following results are provided:

- The maximum plastic strain and the maximum deflection,

- The maximum/minimum reactions at supports,

- Estimated acceleration of FPSO due to collision events on riser protector,

- Plots of deformed shape and plastic strain contour,

- $\quad$ graph containing kinetic energy and absorbed internal energy.

The maximum plastic strain and deflection results are summarized in Table 8. 
Table 8.

Summary of result data on maximum plastic strain and deflection.

\begin{tabular}{|c|c|c|c|c|c|}
\hline \multirow[t]{2}{*}{ Protectors type } & \multicolumn{2}{|c|}{ Plastic strain (\%) } & \multicolumn{3}{|c|}{ Deflection (meters) } \\
\hline & Max. Results & Criteria & Max. Results & Criteria & Margin $^{* *}$ \\
\hline Riser & 4.12 & 15 & 2.124 & $\begin{array}{l}300 \mathrm{~mm} \text { clearance } \\
\text { to risers }\end{array}$ & 0.321 \\
\hline \multirow[t]{2}{*}{ AFT mooring } & \multirow[t]{2}{*}{5.95} & \multirow[t]{2}{*}{15} & 1.282 & \multirow{6}{*}{$\begin{array}{l}\text { Not to contact } \\
\text { with protected } \\
\text { structures }\end{array}$} & 0.559 \\
\hline & & & $0.644 *$ & & 0.649 \\
\hline \multirow[t]{2}{*}{ FWD mooring } & \multirow[t]{2}{*}{7.75} & \multirow[t]{2}{*}{15} & 1.341 & & 0.500 \\
\hline & & & $1.102 *$ & & 0.176 \\
\hline PORT caisson & 7.82 & 15 & 1.051 & & 1.524 \\
\hline STBD caisson & 7.99 & 15 & 1.049 & & 1.574 \\
\hline
\end{tabular}

The results show that all the protectors sustain plastic strain of less than $8 \%$, which is about half of the critical plastic strain. This means that all the protectors sustain excessive stress of yield and deform permanently due to the accidental collision events by a supply vessel; however, they do not fail. The maximum deflection of the riser protector is $2.124 \mathrm{~m}$, which is a sufficient margin considering the design criteria of $300 \mathrm{~mm}$ clearance to the risers.

The mooring protectors deform up to $1.282 \mathrm{~m}$ and 1.341 $\mathrm{m}$ at the parallel part of AFT and FWD mooring protector respectively. The results also show that the slanted parts of protectors in the way of No.3 stringer have not been contacted by mooring chain stoppers including related structures.
The maximum deflections of $1.051 \mathrm{~m}$ and $1.049 \mathrm{~m}$ for each PORT and STBD caisson protector show that collision events due to a supply vessel do not cause any contact between protectors and seawater lift caissons. Table 9 gives the summarized maximum deflections for each protector.

Reactions on the supports are obtained to be used as design loads of supporting structures of the appurtenances. To check whether the resultant acceleration of the FPSO due to the collision events on riser protector by a supply vessel affects the design basis of topside structures, the resultant translational acceleration of FPSO is estimated as following way:

Step 1. The maximum sum of reactions at the supports due to the collision on riser protector is calculated as 5,990 kN.

Table 9.

Summary of maximum deflection for protectors.

\begin{tabular}{llll} 
Protector & Colliding & Load Case & Deflection [m] \\
\hline \multirow{2}{*}{ Risers } & Bow & LC1 & 1.682 \\
\cline { 2 - 4 } & Side & LC10 & 1.071 \\
\hline \multirow{2}{*}{ AFT Mooring } & Bow & LC1 & 1.110 \\
\cline { 2 - 4 } & Side & LC9 & 1.282 \\
\hline FWD Mooring & Bow & LC1 & 1.206 \\
\hline PORT Caisson & Side & LC9 & 1.341 \\
\hline STBD Caisson & Bow & LC6 & 0.933 \\
\cline { 2 - 4 } & Side & LC13 & 1.051 \\
\hline
\end{tabular}


Step 2. The minimum displacement of FPSO is 147,825 tons at the loading No. 1101 - normal towing condition.

Step 3. The lateral acceleration is estimated with the assumption that the FPSO will behave as a rigid body: $\mathrm{F} / \mathrm{m}=$ $5,990 \mathrm{kN} / 147,825=0.0405 \mathrm{~m} / \mathrm{s}=0.004 \mathrm{~g}$.

Finally, there is no need for concern about the additional effect of topsides due to the ship's collision-induced inertia because the induced inertia is too low in comparison with the design lateral acceleration.

Buckling may be concerned at the ship collision in the way of the support member giving very high reaction into the hull structure; So, LC10 of the protector of PORT Seawater Lift Caisson was chosen as a critical loading case.

From the FE results, the member in the way of the impact had the sectional force of $140 \mathrm{kN}$ and the bending moment of $640 \mathrm{KN}-\mathrm{m}$ at the load case. The evaluation was done based on AISC Code (2001). Boundary condition was assumed to both ends fixed. Considering the scantling of member of Outer Diameter (OD) $550 \times 30$, the permissible force was calculated to around $1,000 \mathrm{kN}$, in which the unity check value was only 0.32 (i.e. <1.0) for accidental design factor of 1.0 (i.e. oall $=1.0 \sigma_{\mathrm{y}}$ ). Finally, the buckling is not the matter of concern. The collision was a side-on event, which concerns only two (2) members.

\section{KINETIC ENERGY AND INTERNAL ENERGY}

To check whether the collision simulations are carried out properly, the kinetic energy of the supply vessel and the absorbed internal energy of the protectors are plotted based on time. Most cases show that the kinetic energy starts from the required energy level, and the internal energy increases up to the required energy level. These results reveal that the loadings are properly applied and the simulations are carried out reasonably.

Some cases show that the kinetic energy is not reduced to zero and, hence, the internal energy does not absorb the required energy level. The reason may be that the structure is so stiff that the striking body is bounded before its kinetic energy is consumed. The crew boat collision events show this phenomenon.

The detailed results about the energy level change for all the load cases are shown in Figures 21 to 26. Design loads for the foundation of protectors are summarized in Table 10.

Table 10.

Summary of design loads for protector's foundation.

\begin{tabular}{|c|c|c|c|c|c|c|c|c|c|c|c|c|}
\hline Item & Fx & & Fy & & $\mathrm{Fz}$ & & $\mathrm{Rx}$ & & Ry & & $\mathrm{Rz}$ & \\
\hline & $\min$ & $\max$ & $\min$ & $\max$ & $\min$ & $\max$ & $\min$ & $\max$ & $\min$ & $\max$ & $\min$ & $\max$ \\
\hline Risers & $-2,640$ & 2,630 & $-4,010$ & 813 & $-2,220$ & 5,700 & - & - & - & - & - & - \\
\hline AFT Mooring & $-3,280$ & 4,340 & $-1,370$ & 1,180 & $-1,220$ & 9,950 & $-2,320$ & 2,860 & $-5,800$ & 4,900 & $-1,790$ & 1,710 \\
\hline FWD Mooring & $-2,610$ & 2,610 & $-1,070$ & 1,110 & $-6,530$ & 4,610 & $-2,460$ & 2,520 & $-4,090$ & 4,330 & $-9,450$ & 6,540 \\
\hline PORT Caisson & $-5,120$ & 1,770 & $-1,070$ & 1,030 & $-1,610$ & 13,400 & $-3,030$ & 3,080 & $-8,570$ & 4,730 & -289 & 348 \\
\hline STBD Caisson & $-3,540$ & 1,360 & -696 & 619 & $-1,190$ & 5,830 & $-1,500$ & 1,530 & $-6,150$ & 3,850 & -203 & 253 \\
\hline (Unit: $k N, k N-m$ ) & & & & & & & & & & & & \\
\hline
\end{tabular}



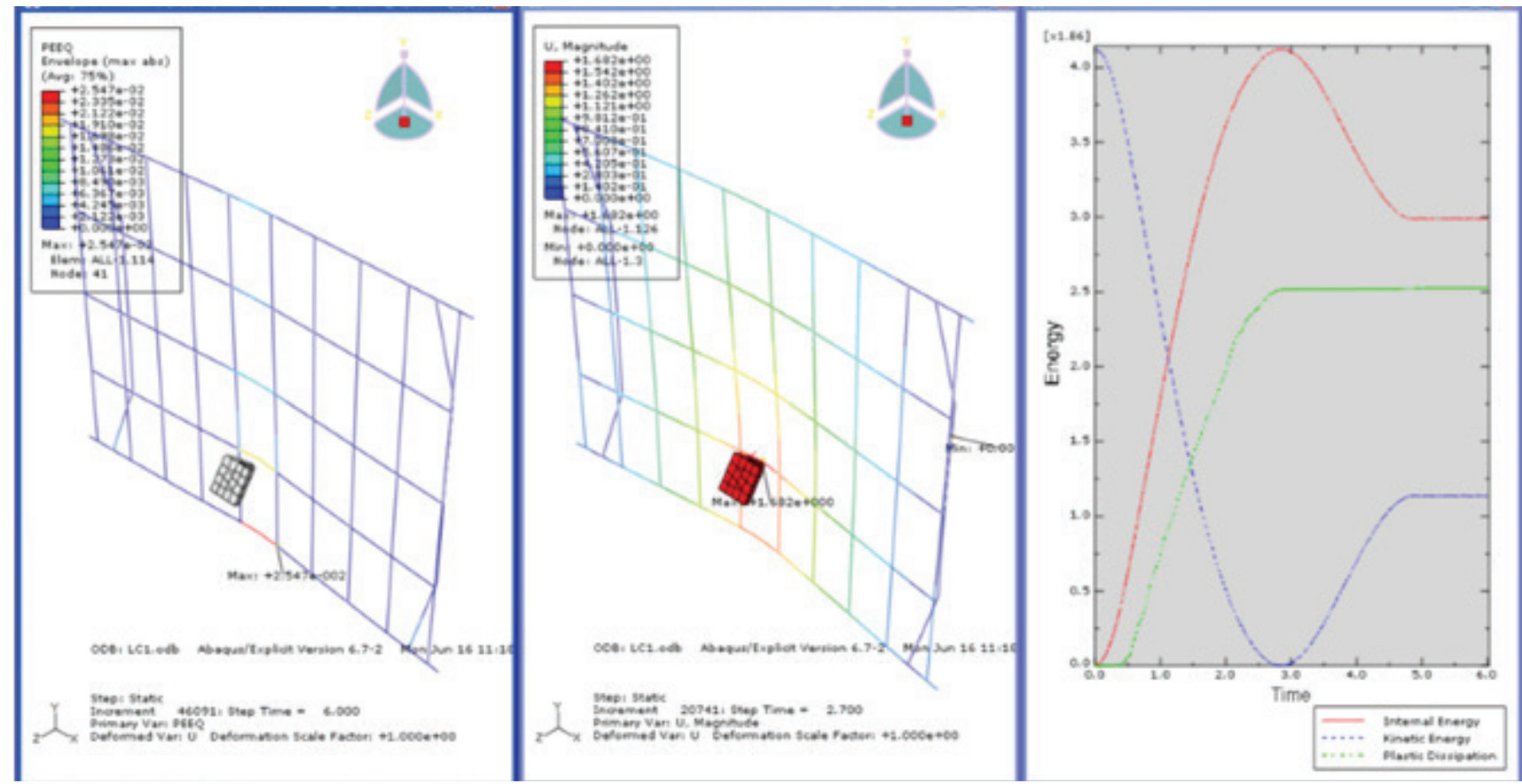

Figure 21.

Results of LC 1 of riser protector (plastic strain, deflection, energy levels).

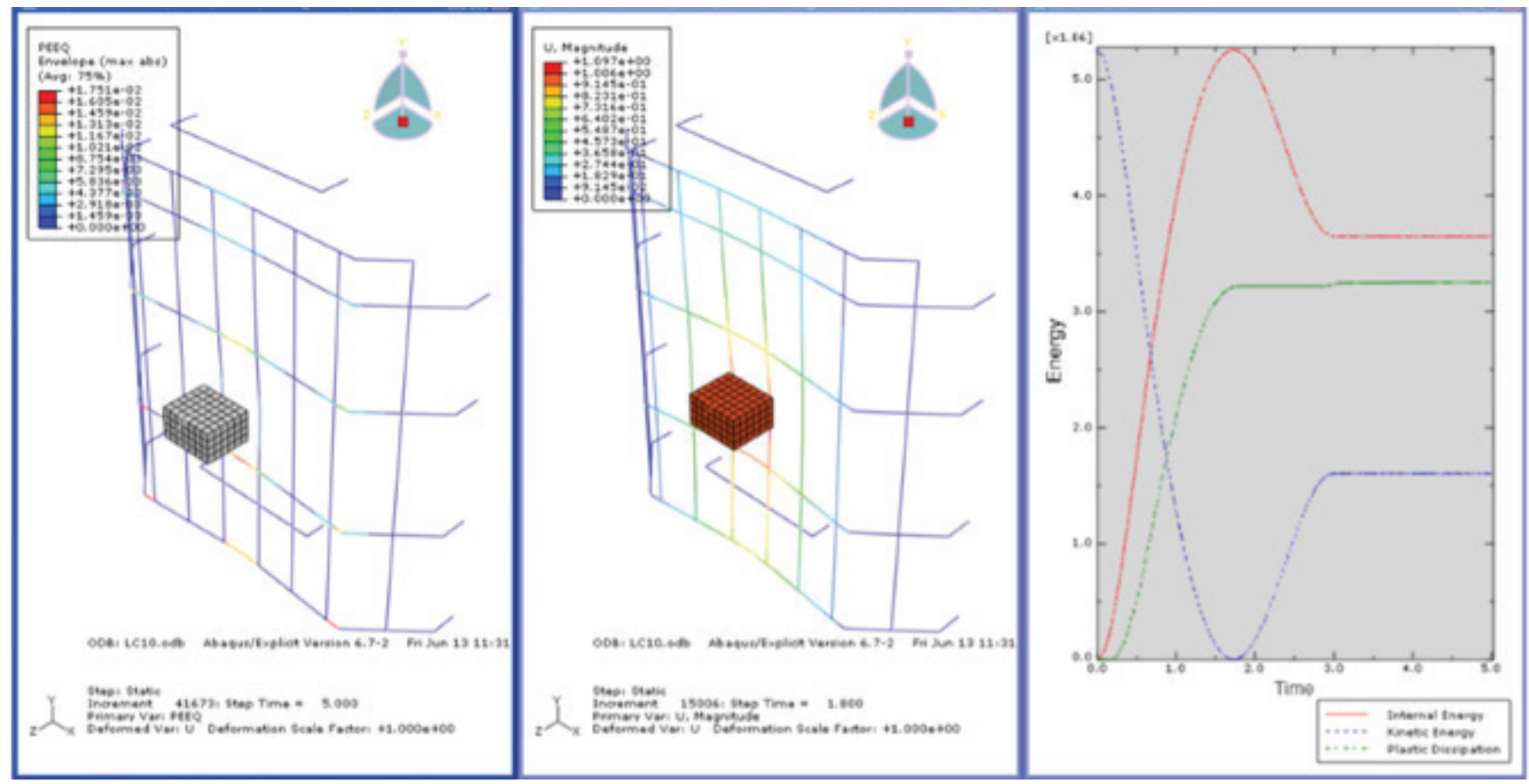

Figure 22.

Results of LC 10 of riser protector (plastic strain, deflection, energy levels). 


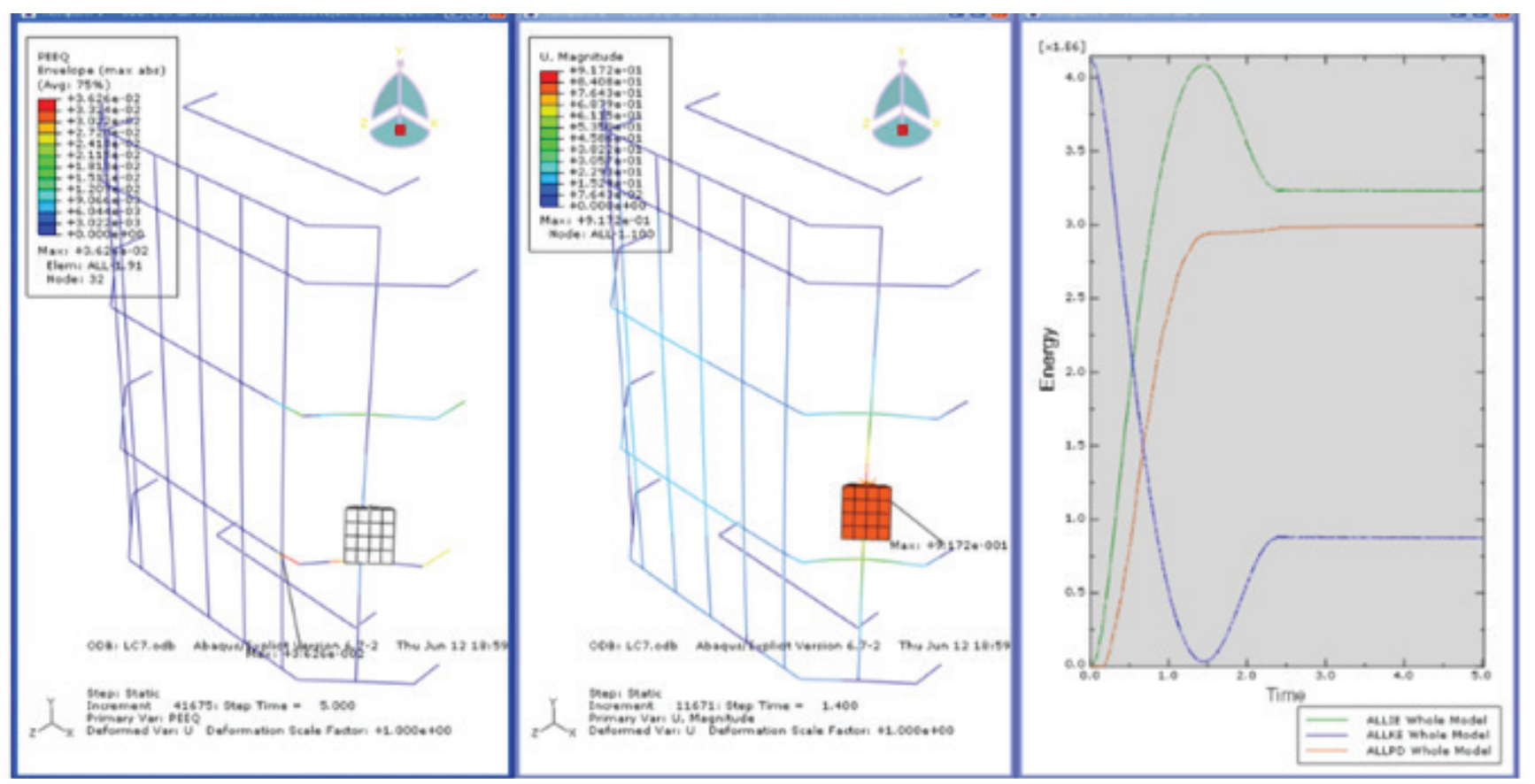

Figure 23.

Results of LC 7 of FWD mooring protector (plastic strain, deflection, energy levels).

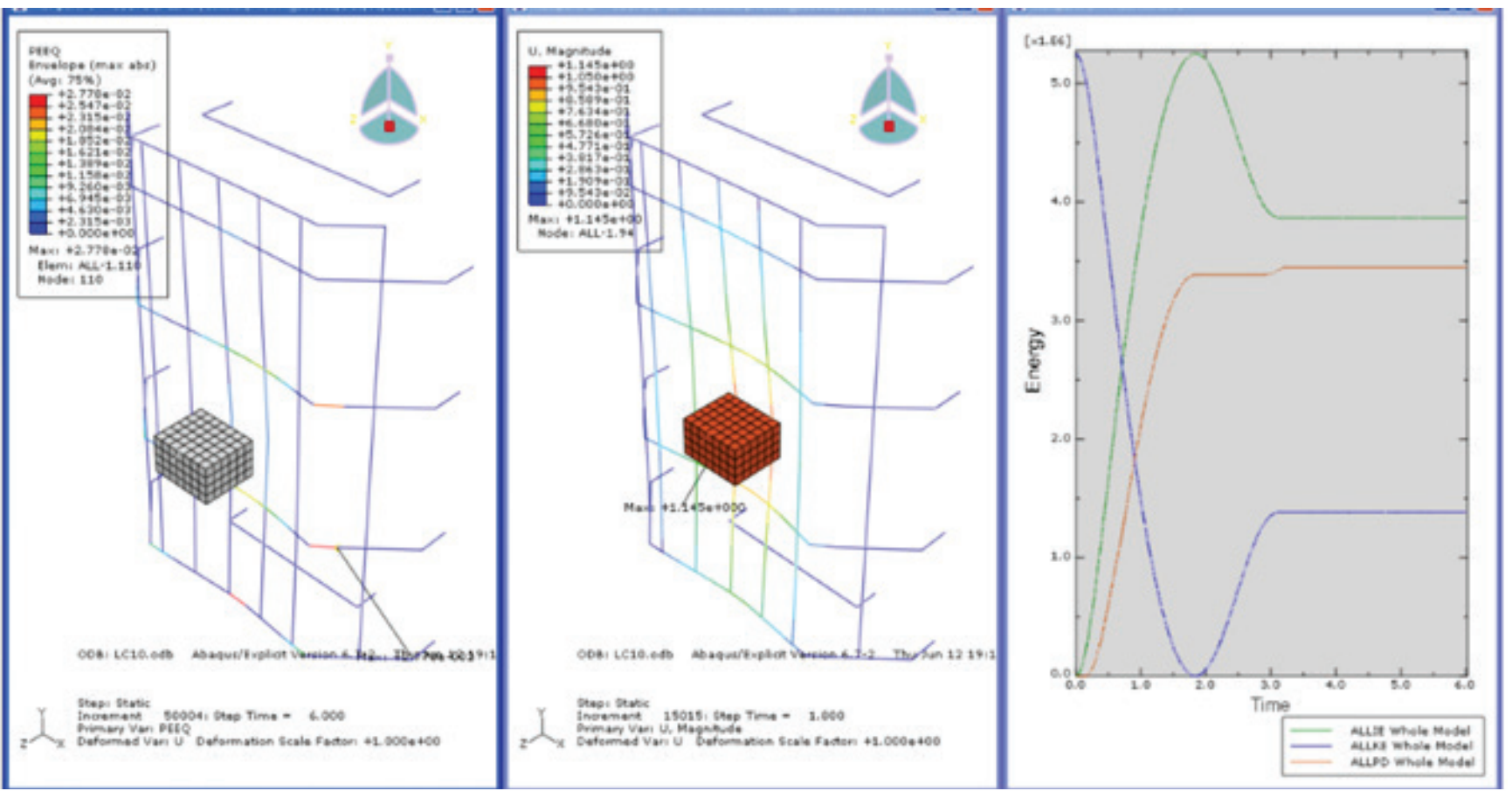

Figure 24.

Results of LC 10 of FWD mooring protector (plastic strain, deflection, energy levels). 


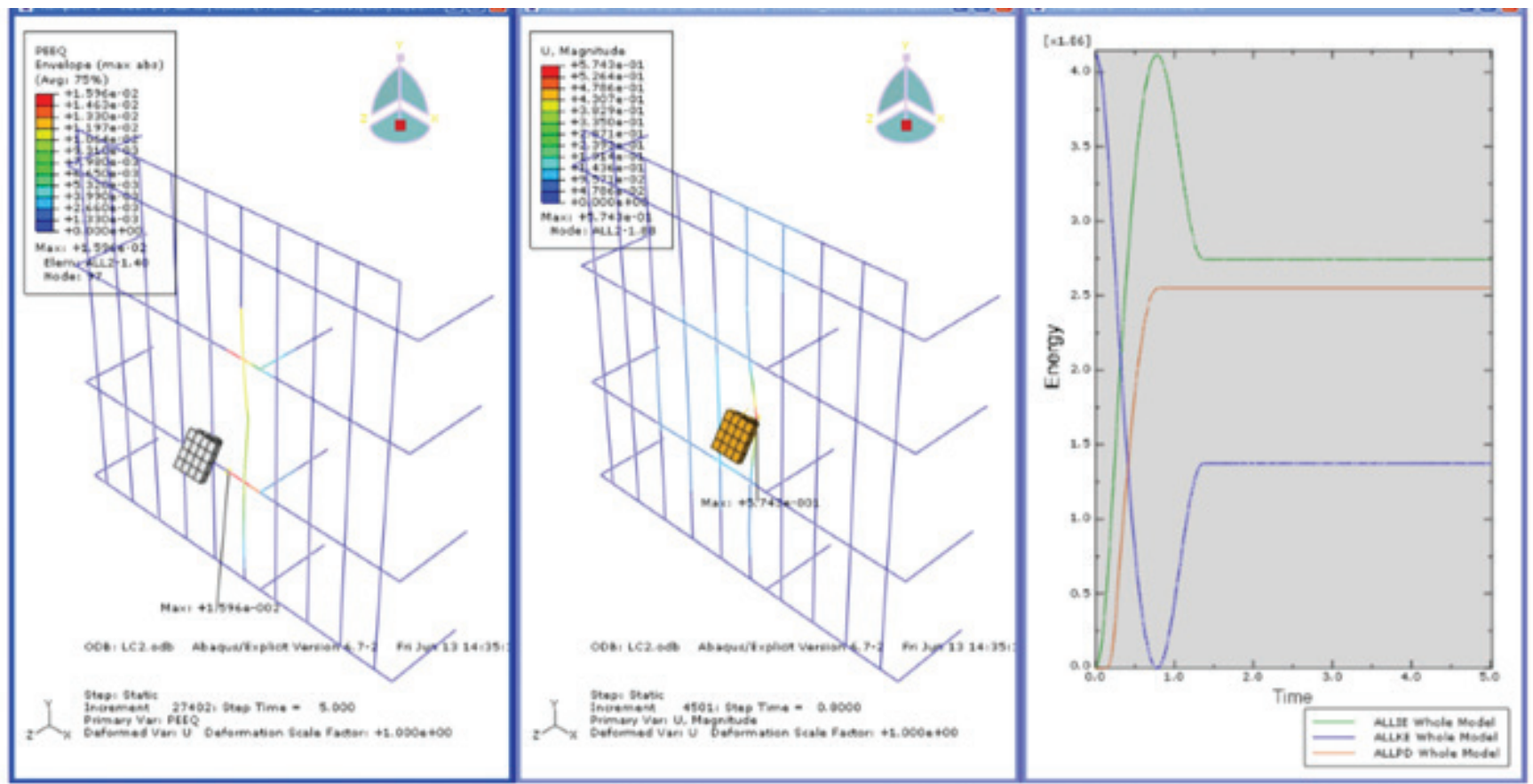

Figure 25.

Results of LC 2 of PORT seawater lift caisson protector (plastic strain, deflection, energy levels).
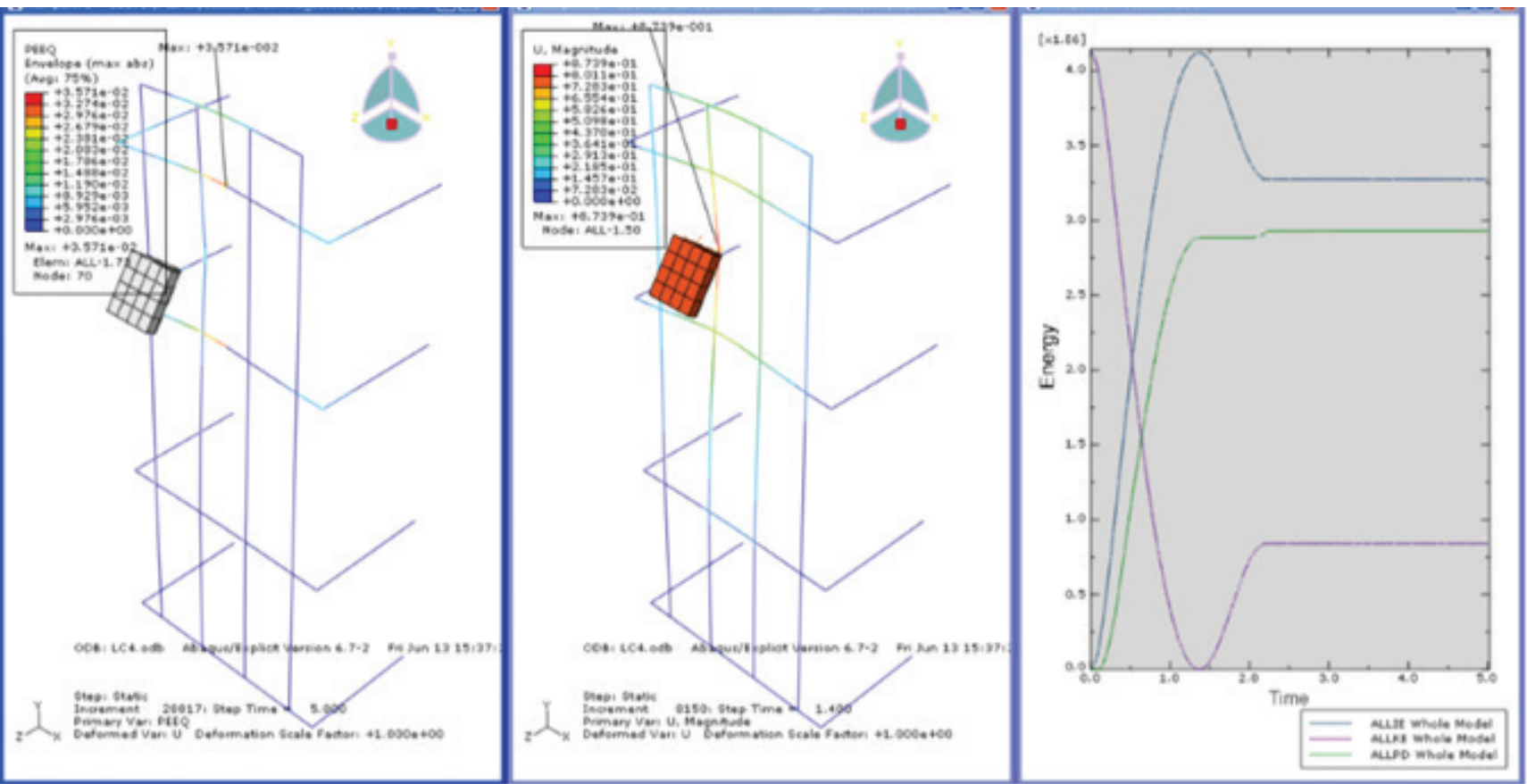

Figure 26.

Results of LC 4 of STBD seawater lift caisson protector (plastic strain, deflection, energy levels). 


\section{CONCLUSION}

Caissons for seawater lift and discharge are normally positioned on the side shell structure. The design should consider the handling requirements for installation, and onsite deployment and maintenance. On the other hand, external vertical caissons fitted with strainer and submerged lift pump for seawater intake, running along the side shell are used. These external vertical caissons should be protected against collision and designed for an easy maintenance.

The collision impact analysis shows that while some parts of the protective parts are permanently deformed by collision events, there is no failure based on the NORSOK standard plastic strain criteria in which the critical plastic strain for HT36 steel grade is specified as $15 \%$.

Bow collision is being simulated by one (1) contact point instead of a surface area, which might produce severer results since it is certain that the bow of the striking vessel is blunt. Furthermore, even though the supply vessel has a beam of over $90 \mathrm{~m}$, only two (2) vertical beams are taken into consideration, which is also very conservative.

The maximum deflections were checked, and no contact was found between the protectors and the protected structures. To verify if the collision simulations are performed correctly, the supply vessel's kinetic energy and the protector's absorbed internal energy were tested during collision events. In most cases, the absorbed internal energy arises to the required energy level, but in some cases all the kinetic energies are not consumed during collision events due to the relatively high protector rigidity.

The maximum deflection of the riser protector is $2.124 \mathrm{~m}$, which is aa sufficient margin considering the design criteria of $300 \mathrm{~mm}$ clearance to the risers.

The mooring protectors deform up to $1.282 \mathrm{~m}$ and 1.341 $\mathrm{m}$ at the parallel part of AFT and FWD mooring protectors respectively. The results also show that the slanted parts of protectors in the way of No.3 stringer have not been contacted with mooring chain stoppers including related structures.

The maximum deflections of $1.051 \mathrm{~m}$ and $1.049 \mathrm{~m}$ for each PORT and STBD caisson protector show that the collision events due to the supply vessel do not cause any contact between protectors and seawater lift caissons.

These results show that the loadings have been properly applied and the simulations have been carried out reasonably.
As such, the findings of this research should be informative in the safe design of FPSO units.

\section{REFERENCES}

ABAQUS, 2013. 6.13. User Guide Documentation, Dassault Systems, 2013.

AISC, 2001. Manual of Steel Construction, Load and Resistance Factor Design, Part 16 Specifications and Codes, 3rd Ed.

Cho, S.-R. et al., 2017. Development of simple design-oriented procedure for predicting the collision damage of FPSO caisson protection structures. Ocean Engineering, 142, pp.458-469. Available at: http://dx.doi.org/10.1016/j.oceaneng.2017.07.036.

DNV GL Rules for Classification, 2019. Hull Structural Design Ships with Length 100 meters and Above, Part 3, Chapter 1.

DNVGL-OS-C102, 2019. DNVGL Offshore Standard, Høvik, Det Norske Veritas, Norway.

DNVGL-RP-C208, 2019. Determination of Structural Capacity by Non-linear FE Analysis Methods, Recommended Practice, Høvik, Det Norske Veritas, Norway.

Hagen SA., 2018. Damage Assessment of Sevan 1000 FPSO Subjected to Impacts from Shuttle Tankers, Master thesis, Norwegian University of Science and Technology, Norway.

Ju, H.-B. \& Jang, B.-S., 2019. A simplified method for assessing safety of ship collision event. Trends in the Analysis and Design of Marine Structures, pp.218-224. Available at: http://dx.doi.org/10.1201/9780429298875-25.

Ning, X., Zhang, B.L. \& Tallavajhula, S., 2013. Structural Integrity of a Spar in Collision With a Large Supply Vessel. Volume 2A: Structures, Safety and Reliability. Available at: http://dx.doi.org/10.1115/omae2013-10213.

NORSOK Standard, 2004a. Design of Steel Structure N-004, Rev.2 October 2004

NORSOK Standard, 2004b. Materials selections M-001, Rev.4 August 2004

Ozguc, O., 2015. Vessel Impact Analysis for Riser Protection Frame and Protection Net Supports on Semi-submersible Offshore Structures, Journal of GIDB, 3, pp. 3-22.

Ozguc, O., 2017. Structural damage of ship-FPSO collisions. Journal of Marine Engineering \& Technology, 18(1), pp.1-35. Available at: http://dx.doi.org/10.1080/20464177.2017.1359387.

The 20th International Ship and Offshore Structures Congress - ISSC, 2018. Committee V.1 Accidental Limit States, Proceedings of the 20th International Ship and Offshore Structures Congress Volume II - M.L.

Wang, G. \& Pedersen, P.T., 2007. A Literature Review of Risk Assessment of ShipFPSO Collisions. Volume 2: Structures, Safety and Reliability; Petroleum Technology Symposium. Available at:

http://dx.doi.org/10.1115/omae2007-29760.

Zhang, S., 1999. The Mechanics of Ship Collision (PhD Thesis). Technical University of Denmark, Lyngby. 